\title{
Development of a neurotoxicity assay that is tuned to detect mitochondrial toxicants
}

\author{
Johannes Delp ${ }^{1,2} \circledast$. Melina Funke ${ }^{1} \cdot$ Franziska Rudolf $^{1} \cdot$ Andrea Cediel $^{3}$. Susanne Hougaard Bennekou ${ }^{4}$.

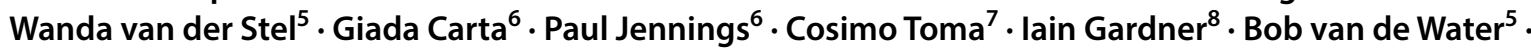 \\ Anna Forsby ${ }^{3,9} \cdot$ Marcel Leist $^{1}$
}

Received: 5 March 2019 / Accepted: 7 May 2019 / Published online: 12 June 2019

(c) The Author(s) 2019

\begin{abstract}
Many neurotoxicants affect energy metabolism in man, but currently available test methods may still fail to predict mito- and neurotoxicity. We addressed this issue using LUHMES cells, i.e., human neuronal precursors that easily differentiate into mature neurons. Within the NeuriTox assay, they have been used to screen for neurotoxicants. Our new approach is based on culturing the cells in either glucose or galactose (Glc-Gal-NeuriTox) as the main carbohydrate source during toxicity testing. Using this Glc-Gal-NeuriTox assay, 52 mitochondrial and non-mitochondrial toxicants were tested. The panel of chemicals comprised 11 inhibitors of mitochondrial respiratory chain complex I (cI), 4 inhibitors of cII, 8 of cIII, and 2 of cIV; 8 toxicants were included as they are assumed to be mitochondrial uncouplers. In galactose, cells became more dependent on mitochondrial function, which made them 2-3 orders of magnitude more sensitive to various mitotoxicants. Moreover, galactose enhanced the specific neurotoxicity (destruction of neurites) compared to a general cytotoxicity (plasma membrane lysis) of the toxicants. The Glc-Gal-NeuriTox assay worked particularly well for inhibitors of cI and cIII, while the toxicity of uncouplers and non-mitochondrial toxicants did not differ significantly upon glucose $\leftrightarrow$ galactose exchange. As a secondary assay, we developed a method to quantify the inhibition of all mitochondrial respiratory chain functions/ complexes in LUHMES cells. The combination of the Glc-Gal-NeuriTox neurotoxicity screening assay with the mechanistic follow up of target site identification allowed both, a more sensitive detection of neurotoxicants and a sharper definition of the mode of action of mitochondrial toxicants.
\end{abstract}

Keywords Neurotoxicity $\cdot$ Mitotoxicity $\cdot$ Metabolic reprogramming $\cdot$ High-throughput toxicity screening $\cdot$ High content imaging $\cdot$ Mechanistic safety assessment

\begin{tabular}{|c|c|c|c|}
\hline \multicolumn{2}{|c|}{ Abbreviations } & \multirow[t]{2}{*}{$\operatorname{FAD}\left(\mathrm{H}_{2}\right)$} & \multirow{2}{*}{$\begin{array}{l}\text { Flavin adenine dinucleotide (FAD: oxi- } \\
\text { dized, FADH2: reduced) }\end{array}$} \\
\hline ADP & Adenosine triphosphate & & \\
\hline AOP & Adverse outcome pathway & FCCP & Carbonyl cyanide-4-(trifluoromethoxy) \\
\hline Asp & L-Aspartate & & phenylhydrazone \\
\hline ATP & Adenosine diphosphate & G6P & Glucose-6-phosphate \\
\hline \multirow[t]{2}{*}{ cAMP } & N6,2'-O-Dibutyryladenosine $3^{\prime}, 5^{\prime}$-cyclic & Gal1P & Galactose-1-phosphate \\
\hline & monophosphate & GALK & Galactokinase \\
\hline $\mathrm{cI}-\mathrm{V}$ & MRC complex I-V & GALT & Galactose-1-phosphate uridylyltransferase \\
\hline CNS & Central nervous system & GDNF & Glial derived neurotrophic factor \\
\hline \multirow[t]{2}{*}{ Cyt c } & Cytochrome c & Glc1P & Glucose-1-phosphate \\
\hline & & Hex & Hexose, in this study either glucose or \\
\hline \multirow{3}{*}{\multicolumn{2}{|c|}{$\begin{array}{l}\text { Electronic supplementary material The online version of this } \\
\text { article (https://doi.org/10.1007/s00204-019-02473-y) contains } \\
\text { supplementary material, which is available to authorized users. }\end{array}$}} & & galactose \\
\hline & & $\mathrm{HK}$ & Hexokinase \\
\hline & & Lac & Lactate \\
\hline \multirow{3}{*}{\multicolumn{2}{|c|}{$\begin{array}{l}\triangle \text { Marcel Leist } \\
\text { marcel.leist@uni-konstanz.de }\end{array}$}} & Mal & Malate \\
\hline & & MoA & Mode of action \\
\hline & & MPP & 1-Methyl-4-phenylpyridinium \\
\hline
\end{tabular}




$\begin{array}{ll}\text { MRC } & \text { Mitochondrial respiratory chain } \\ \text { NA } & \text { Neurite area } \\ \text { NAD }(H) & \begin{array}{l}\text { Nicotinamide adenine dinucleotide (NAD: } \\ \text { oxidized, NADH: reduced) }\end{array} \\ \text { NPA } & \text { 3-Nitropropionic acid } \\ \mathrm{O}_{2} & \text { Oxygen } \\ \text { OA } & \text { Oxaloacetate } \\ \text { OCR } & \text { Oxygen consumption rate } \\ \text { PC } & \text { Pyruvate carboxylase } \\ \text { PGM } & \text { Phosphoglucomutase } \\ \text { Pyr } & \text { Pyruvate } \\ \text { Q } & \text { Ubiquinone or coenzyme Q } \\ \text { ROS } & \text { Reactive oxygen species } \\ \text { Ser } & \text { L-Serine } \\ \text { SSA } & \text { 5'-Sulfosalicylic acid } \\ \text { TCA } & \text { Citric acid cycle or Krebs cycle or tricarbo- } \\ & \text { nic acid cycle } \\ \text { UDP } & \text { Uridine diphosphate } \\ \text { UDP-GALE } & \text { UDP-glucose 4-epimerase } \\ \text { V } & \text { Viability }\end{array}$

\section{Introduction}

Specific identification of neurotoxicants still remains a problem to be solved, and assay conditions need to be optimized to increase the sensitivity of the available in vitro tests (Schmidt et al. 2017; van Thriel et al. 2017). The metabolic situation of a given cell type is one of the parameters that may be tuned as it is known to be one of the key determinants affecting the type and extent of toxicity triggered by a chemical (Delp et al. 2018a; Latta et al. 2000; Leist et al. 1997b, 1999; Volbracht et al. 1999). Replacement of glucose for galactose in cell culture media was reported to tune cellular metabolism from a primary glycolytic to a predominantly mitochondrial phenotype without impairing ATP production (Reitzer et al. 1979; Robinson et al. 1992).

Mitochondria are key organelles of eukaryotic cells, best known for their central role in energy homeostasis (Zhang and Avalos 2017). However, their failure also affects other cell functions, such as calcium signaling (Huang et al. 2017; Leist and Nicotera 1998), (phospho)lipid metabolism (Wajner and Amaral 2015), neurotransmitter turnover (Leist et al. 1998; Nicotera et al. 1999), amino acid metabolism including urea generation (Porporato et al. 2016) and steroid metabolism (Martin et al. 2016). Mitochondrial dysfunctions may therefore have largely different manifestations in different tissues and metabolic situations. Moreover, such defects may escape detection in commonly used toxicological models due to the compensatory capacities that are often seen in animal models (Blomme and Will 2016). Also, most commonly used cell cultures lack sensitivity, as culture media contain frequently supra-physiological amounts of glucose, and thereby facilitate aerobic glycolysis instead of mitochondrial activity for energy production (Jones and Bianchi 2015; Lunt and Vander Heiden 2011; Reitzer et al. 1979).

Considering the difficulties of detecting mitochondrial toxicity (mitotoxicity) in rodents, it is not surprising that many drugs that had to be withdrawn from the market (e.g., troglitazone and cerivastatin), had later been linked to mitotoxicity (Blomme and Will 2016; Tirmenstein et al. 2002; Westwood et al. 2005). Indeed, a sizable fraction of compounds causing, e.g., drug-induced liver injury are mitotoxicants (Aleo et al. 2014; Begriche et al. 2011; Pessayre et al. 2012; Rana et al. 2018; Tilmant et al. 2018).

The need to obtain data on mitochondrial toxicity has been realized in several large European research projects (Desprez et al. 2018; Dragovic et al. 2016; Jennings et al. 2014; Kinsner-Ovaskainen et al. 2013; Kohonen et al. 2017; Wolters et al. 2018) as well as by the Tox21 program (Attene-Ramos et al. 2015; Xia et al. 2018).

During the past 2 decades, technologies have become available that allow the investigation of cellular oxygen consumption for large numbers of samples. Examples are the Agilent Seahorse devices, with sensors fixed to dedicated plates (Nadanaciva et al. 2012) or various methods using soluble sensors to be added to the cell cultures (Gerencser et al. 2009; O'Riordan et al. 2007). Optimized protocols to permeabilize cells allow detailed studies on individual mitochondrial respiratory chain complexes without the need to isolate mitochondria from cells (Divakaruni et al. 2014; Salabei et al. 2014).

To make cell lines more dependent on mitochondrial metabolism, especially the pharmaceutical industry has developed the approach of reducing glucose availability in test systems like HepG2 hepatoma cells (Blomme and Will 2016; Kamalian et al. 2015; Marroquin et al. 2007; Will and Dykens 2014), mouse embryonal and primary human fibroblasts (Pereira et al. 2012, 2018), leukemia K562 cells (Swiss et al. 2013), or skeletal muscle cells (Dott et al. 2014).

For typical cell lines, $\geq 80 \%$ of the glucose taken up is excreted as lactate, while only $5 \%$ is oxidized in mitochondria. In cells that offered galactose (Gal) instead of glucose (Glc), glycolytic flux is largely reduced, while mitochondrial usage increases to produce sufficient ATP (Reitzer et al. 1979; Robinson et al. 1992). The original Glc-Gal assays used in toxicology, analyze the shift in cytotoxic potency of a test compound in glucose vs galactose culture conditions. More recently, the Glc-Gal assay was combined with global oxygen consumption measurements of intact cells to further verify the impairment of mitochondrial metabolism (Eakins et al. 2016). The Glc-Gal shift conditions were also exploited to identify vital OXPHOS genes and a regulatory network of them (Arroyo et al. 2016; Robinson et al. 1992). 
Neurotoxicity is one of the most frequent drug side effects and involves multiple mechanisms (Bal-Price et al. 2015b; Budnitz et al. 2006). As neurons are highly mitochondriadependent cells, they are particularly susceptible to mitochondrial toxicants (Schmidt et al. 2017). Accordingly, some of the most notorious neurotoxicants, such as carbon monoxide, nitropropionic acid, rotenone and $\mathrm{MPP}^{+}$are mitochondrial respiratory chain inhibitors (He et al. 2017; Leist et al. 1997a, c, 1998; Levy 2017; Nicklas et al. 1985; Nicotera and Leist 1997; Schildknecht et al. 2017; Sherer et al. 2007). One of the few adverse outcome pathways (AOP) fully endorsed by the OECD has mitochondrial dysfunction as the pivotal key event (Bal-Price et al. 2018; Terron et al. 2018). Given this situation, it is surprising that only few toxicological test methods focus on the sensitive detection of mitochondrial neurotoxicants. Typical neuronal in vitro cultures are fed with high glucose concentrations, and galactose assays have so far not been established in this area.

To closer explore the role of mitochondria in neurotoxicity, the European research project EU-ToxRisk has initiated a case study (designated CS4) which investigates the propensity of various mitochondrial inhibitors to cause neurotoxicity (http://www.eu-toxrisk.eu/). Within this context, a broad panel of mitotoxicants was identified as tool compounds to trigger mechanistically diverse types of respiratory dysfunction. This set of compounds (Suppl. Item 1) was used here to refine existing human cell-based neurotoxicity assays.

The new approach methods (NAM) currently available to test neurotoxicity (Barbosa et al. 2015; Forsby et al. 2009; Gustafsson et al. 2010; Harrill et al. 2018; Hendriks et al. 2014; Schmuck and Kahl 2009; Schultz et al. 2015; Terrasso et al. 2015; Wilson et al. 2014) make use of the particular vulnerability of specific sub-populations (Zimmer et al. 2011) or they use functional readouts like specific inhibition of neurite outgrowth (Harrill et al. 2011; Hoelting et al. 2016; Krug et al. 2013), disturbance of network formation (Bal-Price et al. 2015a; Frank et al. 2017) or impaired calcium signaling (Gustafsson et al. 2010; Nordin-Andersson et al. 2003). None of these methods is particularly tuned to identify mitochondrial neurotoxicants.

Therefore, this study was initiated to modify the LUHMES cell-based NeuriTox test (Krug et al. 2013; Stiegler et al. 2011) to detect mitochondrial neurotoxicants more sensitively. The easy availability of high amounts of wellcontrolled neuronal cells makes the LUHMES-based assay suitable for high-throughput screening (Delp et al. 2018b; Schildknecht et al. 2013). These cells can be differentiated homogenously within 5 days into mature neurons (Scholz et al. 2011) that show high sensitivity to toxicants (Gutbier et al. 2018a, b; Tong et al. 2017, 2018; Witt et al. 2017). The conventional NeuriTox test differentiates between blunt cytotoxicity and the specific inhibition of neurite outgrowth to detect neurotoxicants (Delp et al. 2018b; Krug et al. 2013).
In this study, the Glc-Gal shift was explored as expansion of the test protocol. Moreover, a secondary follow-up assay was developed to pinpoint the mode of action of mitotoxicants identified in the new Glc-Gal NeuriTox assay. The link of neurotoxicants to their inhibition of specific parts of the neuronal mitochondrial respiratory chain can be used for hit confirmation of mitotoxicity screens.

\section{Materials and methods}

\section{Materials}

Unless specified otherwise, cell culture reagents (consumables and media) were from Gibco/Thermo Fisher Scientific (Waltham, USA), and fine chemicals (inhibitors, substrates) were from Sigma-Aldrich (Steinheim, GER). Physico-chemical properties, CAS identifiers and literature references of the tested set of chemicals are compiled in Suppl. Item 1.

\section{Assessment of neurotoxicity by human neurite outgrowth assay (NeuriTox)}

LUHMES (Lund human mesencephalic) cells were cultured as previously described (Delp et al. 2018b; Krug et al. 2013; Stiegler et al. 2011). Briefly, proliferating precursor cells were kept in proliferation medium [AdvDMEM/F12 containing $2 \mathrm{mM}$ L-glutamine, $1 \times \mathrm{N} 2$ supplement (Invitrogen)] enriched with $40 \mathrm{ng} / \mathrm{ml}$ recombinant human basic fibroblast growth factor $(\mathrm{R}+\mathrm{D}$ systems) and cultured in a $5 \% \mathrm{CO}_{2} / 95 \%$ air atmosphere at $37{ }^{\circ} \mathrm{C}$. Cell culture dishes and flasks (Sarstedt) were pre-coated with $50 \mu \mathrm{g} / \mathrm{ml}$ polyL-ornithine (PLO) and $1 \mu \mathrm{g} / \mathrm{ml}$ fibronectin (Sigma-Aldrich). Differentiation to post-mitotic neurons was performed by seeding cells at a density of 45,000 cells $/ \mathrm{cm}^{2} \mathrm{kept}$ in proliferation medium for $24 \mathrm{~h}$ and a subsequent medium change to differentiation medium [AdvDMEM/F12 supplemented with $2 \mathrm{mM}$ L-glutamine, $1 \times \mathrm{N} 2$ (Invitrogen), $1 \mathrm{mM} \mathrm{N6}, 2^{\prime}$ $O$-dibutyryl 3',5'-cyclic adenosine monophosphate (cAMP) (Sigma-Aldrich), $1 \mu \mathrm{g} / \mathrm{ml}$ tetracycline (Sigma-Aldrich), and $2 \mathrm{ng} / \mathrm{ml}$ recombinant human glial cell-derived neurotrophic factor (GDNF, R+D Systems)]. After $48 \mathrm{~h}$ of differentiation, cells were detached with $0.05 \%$ trypsin/EDTA (Invitrogen) and seeded into 96 well plates at a density of 100,000 cells/ $\mathrm{cm}^{2}$. In the standard NeuriTox setup, pre-differentiated cells were treated $1 \mathrm{~h}$ after seeding, i.e., on day 2 of differentiation (d2) for $24 \mathrm{~h}$. For the assessment of neurite area on d2, directly before trypsinization, cells were pre-differentiated in 96-well plates and assayed after $48 \mathrm{~h}$ of differentiation. 


\section{Glc-Gal NeuriTox assay}

For the modified Gal-NeuriTox assay, the cells were handled exactly in the same way, but the medium contained $18 \mathrm{mM}$ galactose. To assess the difference between cells grown in glucose (Glc cells) and cells grown in galactose (Gal cells), the same proliferating precursor population was always used for parallel differentiations in the presence of either glucose (Glc medium) or galactose (Gal medium).

\section{Image acquisition and quantification in the neurite assays}

Image acquisition was performed exactly as described previously (Krug et al. 2013; Schildknecht et al. 2013; Stiegler et al. 2011). Briefly, cells were live stained with $1 \mu \mathrm{g} / \mathrm{ml}$ Hoechst $\mathrm{H}-33342$ and $1 \mu \mathrm{M}$ calcein-AM for image acquisition. The neurite area was calculated as the total calceinpositive area corrected for the somatic area, covered by the cell bodies. If cell densities varied from preparation to preparation (e.g., for the Glc Gal comparison of $\mathrm{d} 2$ cells before replating), data were compared between parallel cultures from individual preparations. The apparent neurite area per cell was smaller in high-density cultures, since neurites growing over cell bodies were excluded by the software. For statistical tests, then the pairwise mode was chosen. This was necessary as the applied image quantification algorithm requires equal cell densities. Viable cells were defined by a nucleus with overlapping calcein signal. Nuclei without calcein stain were counted as dead cells. Viability was expressed as viable cells/total cells $\times 100 \%$.

\section{Seahorse assessment of mitochondrial and glycolytic functional parameters of intact LUHMES cells}

Assessment of mitochondrial and glycolytic functionality was performed exactly as described earlier (Delp et al. 2018b). Briefly, d2 LUHMES cells, already cultured for $48 \mathrm{~h}$ in either Glc medium or Gal medium were seeded at a density of 100,000 cells $/ \mathrm{cm}^{2}$ into Agilent Seahorse XFe24 well plates. $24 \mathrm{~h}$ later (on $\mathrm{d} 3$ ), cells were analyzed. The "basal" respiration and acidification were measured in untreated cells; the "maximal respiration" was measured in the presence of $1.5 \mu \mathrm{M}$ carbonyl cyanide-4-(trifluoromethoxy) phenylhydrazone (FCCP); the "maximal acidification" was assessed in Glc cells in the presence of $1 \mu \mathrm{M}$ oligomycin, which blocked mitochondrial energy production and made cells $100 \%$ dependent on glycolysis for energy production. Due to the different situation in Gal cells (dependence on mitochondria), different conditions were chosen here to maximize the galactolytic flux. Mitochondria were uncoupled by $1.5 \mu \mathrm{M}$ FCCP to allow a maximal metabolism of pyruvate which was not secreted as lactate by these cells. Under such conditions, $\mathrm{CO}_{2}$ produced by the TCA might contribute to the acidification. Oxygen consumption rate (OCR) and extracellular acidification rate (ECAR) were always normalized to the cell count. The latter was obtained by including $1 \mu \mathrm{g} / \mathrm{ml} \mathrm{H}-33342$ plus $1 \mu \mathrm{M}$ calcein-AM (final concentrations on the cells) in the last Seahorse injection followed by automated image analysis as described above for the NeuriTox assay [using the Seahorse assay plates on Cellomics CellInsight (Cellomics, Waltham, MA, USA)]

\section{Assessment of the function of individual mitochondrial complexes in permeabilized LUHMES cells}

To study the inhibition of individual mitochondrial respiratory chain (MRC) complexes, proliferating LUHMES cells were seeded into Agilent Seahorse XFe24 well plates at a density of 205,000 or 135,000 cells $/ \mathrm{cm}^{2}$ and were allowed to grow for 1 or 2 days in proliferation medium, respectively. They were used at $24-48 \mathrm{~h}$ after seeding, when they had recovered from replating and reached $95 \%$ confluency, but were not overgrown. For the assay, cells were permeabilized with MAS buffer (220 mM mannitol, $1 \mathrm{mM}$ ADP, $70 \mathrm{mM}$ sucrose, $10 \mathrm{mM} \mathrm{KH_{2 } \mathrm { PO } _ { 4 } , 5 \mathrm { mM } \mathrm { MgCl }}$, $2 \mathrm{mM}$ HEPES, $1 \mathrm{mM}$ EGTA, $4 \mathrm{mg} / \mathrm{ml}$ fatty acid-free $\mathrm{BSA}, \mathrm{pH}=7.2$ ) supplemented with $25 \mu \mathrm{g} / \mathrm{ml}$ digitonin (Salabei et al. 2014). The Seahorse measurements of OCR were started $30 \mathrm{~min}$ after permeabilization. The function of respiratory chain complexes was assessed by a strategy (Salabei et al. 2014) based on applying complex-specific substrates and inhibitors, with exact conditions optimized to LUHMES [cI: substrate was $5 \mathrm{mM}$ Pyr, $2 \mathrm{mM}$ Gln, and $2.5 \mathrm{mM} \mathrm{Mal}$, inhibitor was $0.5 \mu \mathrm{M}$ rotenone; cII: substrate was $10 \mathrm{mM}$ succinate, inhibitor was $5 \mathrm{mM}$ malonate; cIII: substrate was $250 \mu \mathrm{M}$ duroquinol (TCI chemicals Germany, Eschborn, GER), inhibitor was $0.5 \mu \mathrm{M}$ antimycin A; cIV: $125 \mu \mathrm{M}$ TMPD $+2 \mathrm{mM}$ ascorbic acid, no specific inhibitor was used] and the injection strategy is detailed in the results section as part of the seventh figure. Since the measurement was extremely sensitive to cell number variations, the last measurement before the injection of the test substance was used for internal normalization. For each respiratory chain complex, its activity in the presence of solvent control (DMSO) was used as reference to normalize the data for samples exposed to test substances.

\section{Lactate quantification}

To measure the lactate secretion, Glc and Gal cells were seeded at $\mathrm{d} 2$ into fresh (lactate free) medium and cultured 
for $24 \mathrm{~h}$. The lactate concentration in the medium was determined by a commercially available enzymatic assay (Diaglobal LAC142 assay, Berlin, Germany) with a colorimetric endpoint. The amount of lactate produced within $24 \mathrm{~h}$ was normalized to the live cell count. The latter was assessed by H-33342 and calcein-AM staining as described above.

\section{Proteasomal activity}

To quantify the proteasomal activity, cells were cultured and exposed exactly in the same way as for the NeuriTox assay. Parallel plates that were not used to assess viability and neurite outgrowth were used to assess proteasomal activity. Activity measurements were performed exactly as described in (Gutbier et al. 2018b). The assay is based on the replacement of cell culture medium by HBSS buffer containing a cell permeable proteasomal substrate [MeOSuc-Gly-LeuPhe-AMC, $25 \mu \mathrm{M}$ (Bachem, Bubendorf, Switzerland)] after $24 \mathrm{~h}$ of toxicant exposure. AMC fluorescence (ex: $360 \mathrm{~nm}$, em: $465 \mathrm{~nm}$ ) was determined directly after addition of the assay buffer to the cells and after 90 min incubation. The increase in fluorescence was used as a measure of proteasomal activity.

\section{Intracellular ATP}

To assess intracellular ATP content, the plates from the NeuriTox assay were multiplexed with an ATP assay, i.e., after the image analysis on a Cellomics CellInsight, cells were lyzed within the plates. Then, ATP was measured luminometrically, using a commercial reagent mix (Promega CellTiterGlo 2.0) containing luciferase. Data were normalized to DMSO solvent control.

\section{Quantification of aspartate and serine}

Amino acids were quantified as described earlier (Delp et al. 2018a; Secker et al. 2018). Briefly, cells were lyzed on ice with $50 \% \mathrm{MeOH} / \mathrm{H}_{2} \mathrm{O}$ and the lysates were vacuum dried. After reconstitution in 2\% (w/v) 5-sulfosalicylic acid/ $\mathrm{H}_{2} \mathrm{O}$ (SSA), followed by a centrifugation step $(20,000 \times g$, 30 min, $4{ }^{\circ} \mathrm{C}$ ), samples were subjected to a HPLC separation. For detection, a post-column ninhydrin reaction was employed that generated colorimetrically detectable amino acid derivatives that were quantified by their absorbance at $570 \mathrm{~nm}$. To determine amino acid concentrations in the cell culture medium, samples from the cell culture supernatant were obtained. SSA was added to yield a final SSA concentration of $2 \%$. Then, samples were centrifuged (30 min, $4{ }^{\circ} \mathrm{C}, 20,000 \times g$ ) and the supernatant was mixed $1: 1$ with sample dilution buffer $(0.12 \mathrm{M} \mathrm{LiCl}, \mathrm{pH} 2.2)$ and analyzed as described above.

\section{Assessment of neurotoxicity in SH-SY5Y cells}

Human neuroblastoma SH-SY5Y cells were plated in 96-well plates with micro-clear bottom $\left(31,250\right.$ cells $/ \mathrm{cm}^{2}$, Greiner) in $100 \mu \mathrm{l}$ proliferation medium (EMEM supplemented with $10 \%$ fetal bovine serum, $2 \mathrm{mM}$ L-glutamine, $1 \%$ non-essential amino acids, $100 \mu \mathrm{g} / \mathrm{ml}$ streptomycin and $100 \mathrm{U} / \mathrm{ml}$ penicillin) (Gustafsson et al. 2010). Differentiation was initiated $24 \mathrm{~h}$ later (on day 0 ) by exchange to $100 \mu \mathrm{l} /$ well differentiation medium (DMEM:F12, supplemented with $1 \mu \mathrm{M}$ all-trans retinoic acid (RA), $1 \times \mathrm{N} 2$ supplement, $2 \mathrm{mM}$ L-glutamine, $100 \mu \mathrm{g} / \mathrm{ml}$ streptomycin and $100 \mathrm{U} / \mathrm{ml}$ penicillin). All media and supplements were obtained from Gibco (ThermoFisher) except from RA (Sigma). On d3, 50\% of the medium was exchanged. Conventional SH-SY5Y cultures (Glc-SH-SY5Y cells) received fresh differentiation medium on d6, together with the toxicant. Cell cultured in Gal medium (Gal-SH-SY5Y cells) received fresh Gal-differentiation medium (AdvDMEM/ F12, supplemented with $1 \mu \mathrm{M}$ RA, $2 \mathrm{mM}$ L-glutamine and $18 \mathrm{mM}$ galactose (Roth) instead of glucose) on d5 to allow metabolic adaptation. The cells were exposed to toxicants on d6. Test compounds were always added in $10 \mu \mathrm{l}$ of 10 $\times$ concentrated test substances for $24 \mathrm{~h}$. Subsequently, cells were stained with $5 \mu \mathrm{g} / \mathrm{ml} \mathrm{H}-33342$, and $5 \mu \mathrm{M}$ propidium iodide (PI, Sigma) (final concentrations) to assess cell viability, i.e., the fraction of non-PI positive cells (live cells) relative to $\mathrm{H}-33342$ positive cells (total cell count) by automated high content microscopy [ImageXpress Micro (Molecular Devices, UK)]. The cells were imaged using a $10 \times$ objective lens, and the following wavelengths: H-33342 excitation $377 \pm 50 \mathrm{~nm}$, emission $447 \pm 60 \mathrm{~nm}$, $100 \mathrm{~ms}$ exposure time, PI excitation $562 \pm 40 \mathrm{~nm}$, emission $624 \pm 40 \mathrm{~nm}, 400 \mathrm{~ms}$ exposure time.

\section{Curve fitting, data mining and statistics}

For all data shown, at least three independent experiments were performed. Each independent experiment (=biological replicate) consisted of several technical replicates. In the first data processing step, data of the technical replicates were expressed as percent of their respective solvent controls within a biological replicate. After that, technical replicates were averaged, i.e., the mean of all technical replicates of one independent experiment was used as single data point of a biological replicate. Subsequently, the mean of the $\geq 3$ biological replicates was determined, and a measure of variation (SD/SEM) was calculated.

Curve fits were calculated using a four-parameter Hill model with constraints for the upper asymptote to $100 \%$ of solvent-treated samples. The equation of the Hill model was solved for $f(x)=75 \%$ or $50 \%$ to determine the $\mathrm{EC}_{25}$ or $\mathrm{EC}_{50}$, respectively, i.e., the concentration at which the 
A

\section{Galactose}<smiles></smiles><smiles>O=CC(O)C(O)C(O)CO</smiles>

\section{Glucose}

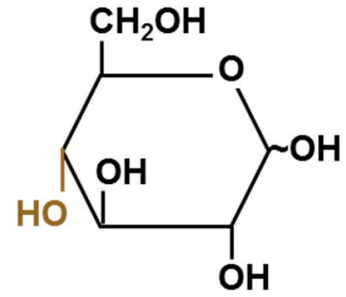

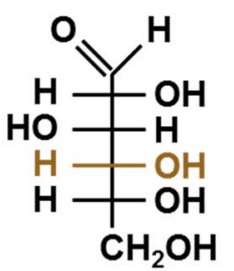

B

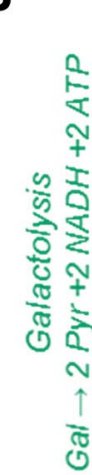

\section{Galactose}

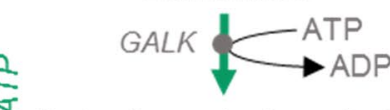

Galactose-1-phosphate

Glucose-1-phosphate

GALT UDP-Glucose

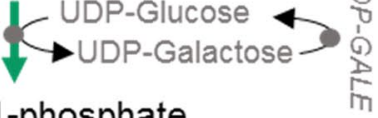

$P G M$

Glucose-6-phosphate Glucose

Glycolysis

Glc $\rightarrow 2$ Pyr +2 NADH +2 ATP

Lactate $\quad$ Pyruvate $\longrightarrow$ Lactate

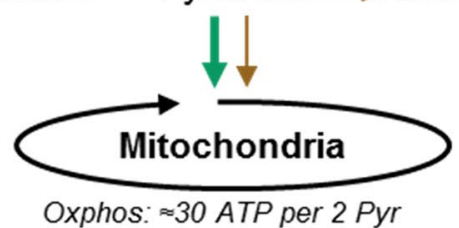

enzyme

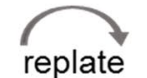

assay

replate

d-1

d2

d3

8

Day of Differentiation

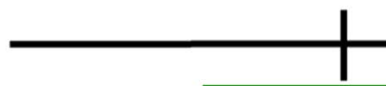

Cell status

Medium supplements

Medium sugar:

- Standard setup (G/C)

- Galactose setup (Gal)

D

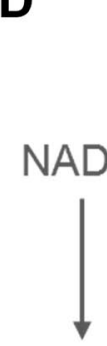

Asp/Mal

Glucose

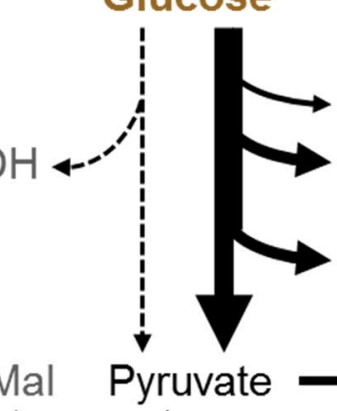

$\downarrow$

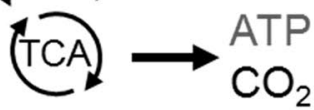

proliferation

bFGF

differentiation

tetracycline, cAMP, GDNF

tetracycline

\section{$18 \mathrm{mM}$ Glc, $0 \mathrm{mM}$ Gal}

$18 \mathrm{mM} \mathrm{Glc}$

$0 \mathrm{mM}$ Glc, $18 \mathrm{mM}$ Gal

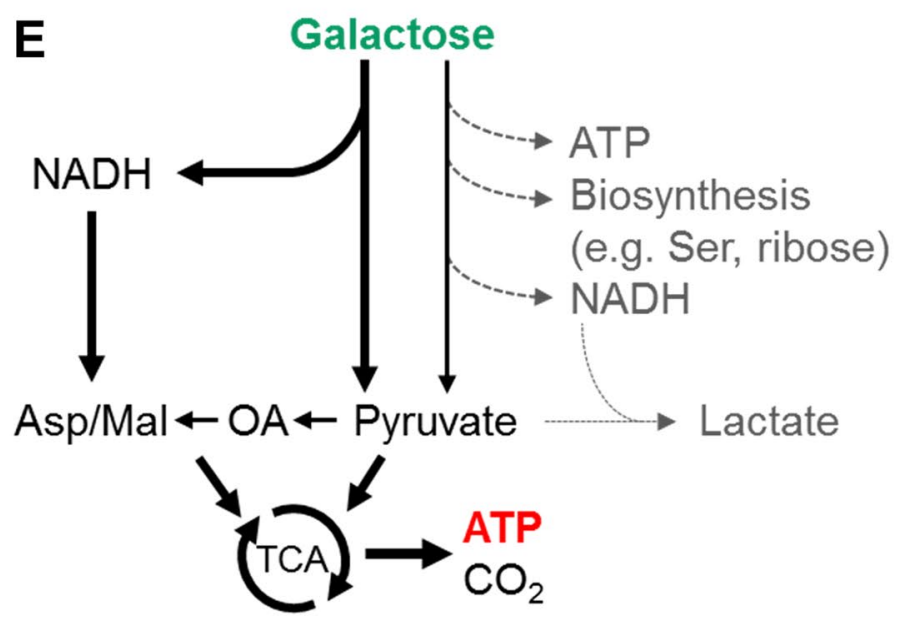

neurite outgrowth inhibiting effect was at $25 \%$ or $50 \%$ of the solvent control. If not stated otherwise, data in the figures are mean \pm SEM and statistical differences between the treatments and the control were evaluated by an analysis of variance (ANOVA) followed by Dunnett's post hoc test $(p<0.05)$. 
४Fig. 1 Theoretical background and experimental conditions for substituting glucose by galactose. a Structural representations of the two hexose C4-epimers glucose (Glc) and galactose (Gal). Both the open chain (aldehyde) and the cyclized (pyranose hemiacetal) forms differ in the position of their $\mathrm{C} 4$ hydroxyl group. b Metabolic pathways for the catabolism of both sugars. While Glc becomes directly phosphorylated by hexokinase (HK) to glucose-6-phosphate (G6P), Gal is metabolized through the Leloir pathway to G6P. The Gal metabolism starts with the phosphorylation of Gal to galactose-1-phosphate (Gal1P) by galactokinase (GALK). In the next step, Gal1P reacts with UDP-glucose to G6P plus UDP-galactose, catalyzed by galactose-1-phosphate uridylyltransferase (GALT). The UDP-galactose is recycled back, without energy expenditure, to UDP-glucose by UDP-glucose 4-epimerase (UDP-GALE). The generation of G6P via either pathway requires energy substrates equivalent to one ATP. The downstream reactions leading from G6P to pyruvate (Pyr) are formally identical for Glc and Gal. However, it has been shown for various cell types that overall glycolysis proceeds faster than galactolysis, and that the surplus NADH generated from Glc is preferentially reacting with Pyr to form lactate (Lac). The NADH formed during galactolysis appears to be preferentially used for cellular biosynthesis or for full oxidation within mitochondria. c Differentiation scheme of LUHMES cells cultured for the Glc-Gal-NeuriTox assay. LUHMES cells are kept proliferating in bFGF-containing proliferation medium with $18 \mathrm{mM}$ Glc. Differentiation was initiated by placing the cells in differentiation medium with either $18 \mathrm{mM}$ Glc (standard Glc setup) or $18 \mathrm{mM} \mathrm{Gal}$ (galactose setup). On d2 of differentiation, cells were detached and replated in medium with the same sugar as before. GDNF and cAMP were added to the differentiation medium from $\mathrm{d} 0$ to $\mathrm{d} 2$, but not for $\mathrm{d} 2-\mathrm{d} 3$. One hour after replating, the cells were treated with toxicants. After $24 \mathrm{~h}$, the cells were analyzed for neurite outgrowth and viability by automated high content imaging. Visualization of the different pathway usage assumed to occur in cells cultured with Glc (d) vs Gal (e). Hexoses can be metabolized to Pyr with the primary objective to enter Pyr as well as the excess NADH into the mitochondria to generate ATP via the mitochondrial respiratory chain (MRC) activity. Alternatively, sugars may be converted to other cellular metabolites, such as serine (Ser) and lactate, without ever entering the mitochondria. In this case, all/most ATP required by the cells would need to be generated by a high glycolytic flux. $\mathbf{d}$ It is assumed that cells grown in Glc predominantly use the second variant of metabolism. The citric acid cycle (TCA) would be used only to a minor extent. e Cells cultured in Gal are assumed to use galactolysis to a small extent to generate Lac, ATP, and other metabolites. The predominant fate of Pyr would be to feed the TCA to generate $\mathrm{ATP}+\mathrm{CO}_{2}$. The excess NADH (not used for Lac synthesis) would be channeled to the mitochondria as further fuel for the MRC for the generation of ATP. An increased flux of NADH to mitochondria via the malate/aspartate shuttle would be facilitated by the generation of oxaloacetate (OA) from $\mathrm{Pyr}$

\section{Results and discussion}

\section{Comparison of basic metabolic, morphological and functional features of cells cultured in glucose vs galactose}

The most important sugar for cellular energy supply is glucose (Glc), but most cells express transporters and a metabolic machinery to use related carbohydrates. One of these is galactose $(\mathrm{Gal})$, the $\mathrm{C} 4$ epimer of glucose. Gal and Glc are nearly identical molecules, differing only in the stereospecific conformation of the hydroxyl group at carbon atom 4 (Fig. 1a).

For energy production, all sugars are converted to one of the canonical glycolysis intermediates, and from this stage on, they all follow the same unified pathway to form pyruvate (Pyr). Gal metabolism (galactolysis) differs from Glc metabolism (classical glycolysis) only in the entry steps. Glc is directly (single enzymatic step) converted to glucose6-phosphate (G6P), the first glycolytic metabolite; the conversion of Gal to G6P requires three enzymatic steps, plus a recycling reaction, i.e., the co-ordinate function of four enzymes. However, contrary to erroneous reports in the literature, the conversion of Glc and Gal to G6P requires the same amount of energy (i.e., one ATP per sugar). If galactolysis and glycolysis produce different amounts of ATP, then this must be for kinetic reasons, i.e., because of a different flux/speed of the final Pyr formation. Galactolytic turnover may be attenuated either due to slower import of Gal, or a less rapid conversion to G6P. The theoretical maximal yield of reducing equivalents (NADH) and energy equivalents (ATP from glycolysis and mitochondrial metabolism) is the same for the two sugars (Fig. 1b).

To test the effect of Gal vs Glc supply to neurons, the established NeuriTox test protocol was modified. In a parallel experimental setup, starting with the same proliferating culture, LUHMES cells were either differentiated in Glc or Gal-containing differentiation medium to allow a full adjustment to the metabolic conditions at the time of the toxicant treatment (i.e., on $\mathrm{d} 2$ of differentiation, after replating). Neurite outgrowth and general cell viability were assessed after $24 \mathrm{~h}$ of treatment for both assay conditions (Fig. 1c).

We expected that cells would use different strategies of ATP production, when cultured in Glc vs Gal, as described earlier for non-neuronal cells. Our assumption was that cells in Glc generate most of their ATP as well as some metabolites like serine and ribose from glycolysis. The abundant NADH and pyruvate generated by this metabolic condition are transformed to lactate, which is then secreted, and to $\mathrm{NAD}^{+}$which allows cells further glycolytic flux. Mitochondrial metabolism, e.g., the citric acid cycle (TCA), is not primarily used for energy production (Fig. 1d). For Gal cells, we expected a shift towards a mitochondria-dominated metabolism. Under such conditions, the Pyr produced through galactolysis is used to fuel the TCA and thus respiratory generation of ATP. With a predominantly mitochondrial fate of Pyr, lactate excretion would not be required, and less carbon may be used for biosynthesis. Instead, galactolytic NADH would be transported into the mitochondria via the malate/aspartate shuttle to produce energy. Increased levels of oxaloacetate, formed from pyruvate by pyruvate carboxylase (PC), can increase the mitochondrial/cytosolic exchange of NADH. PC is known to be active in LUHMES cells (Delp et al. 2018a) and to be activated by acetyl-CoA, 

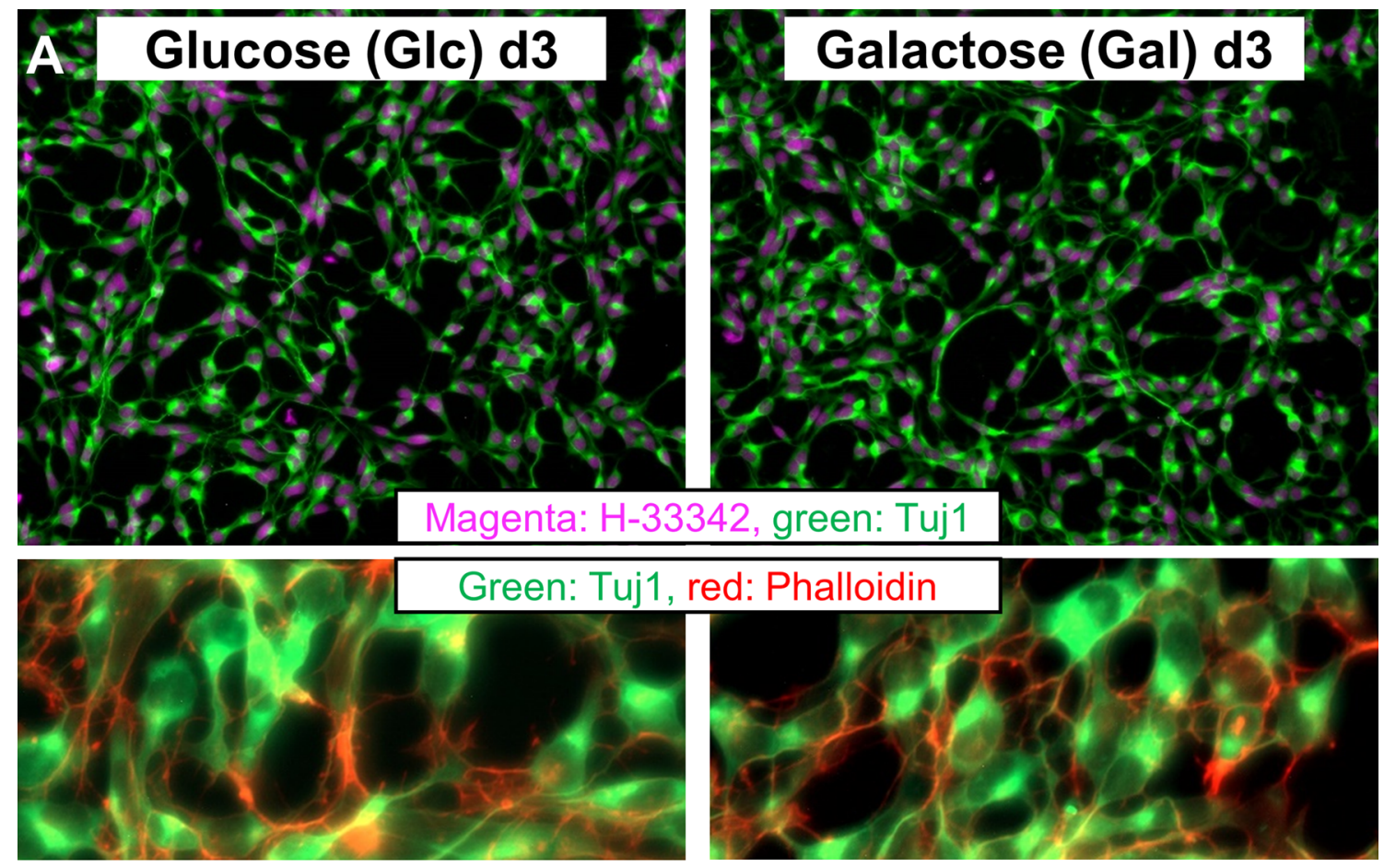
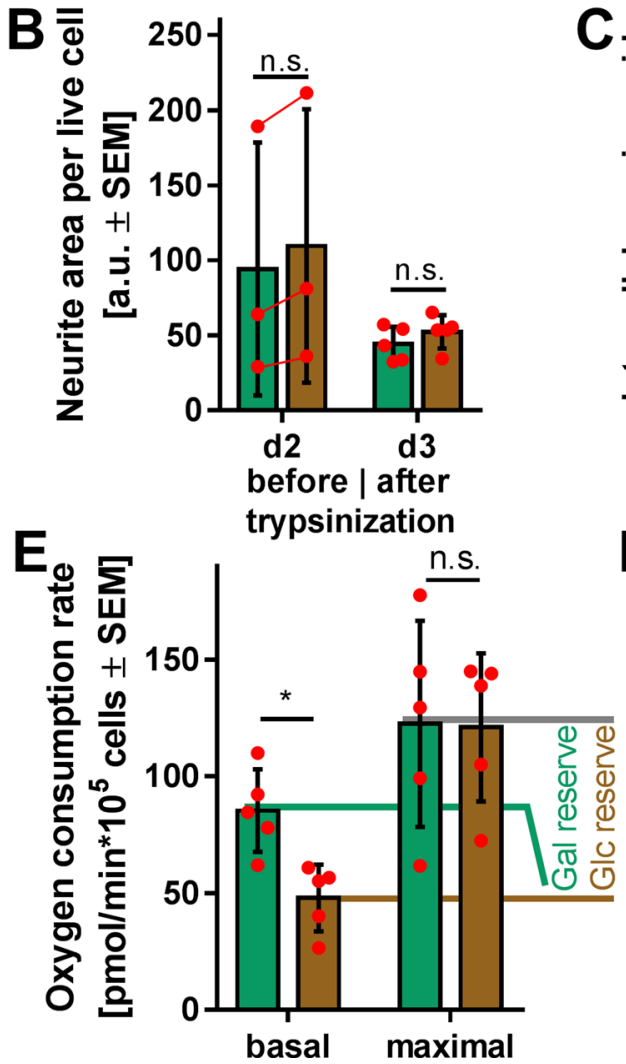

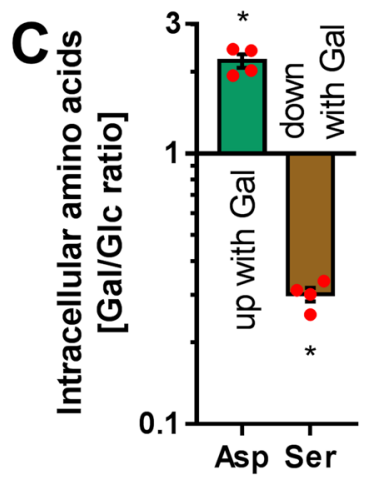

F

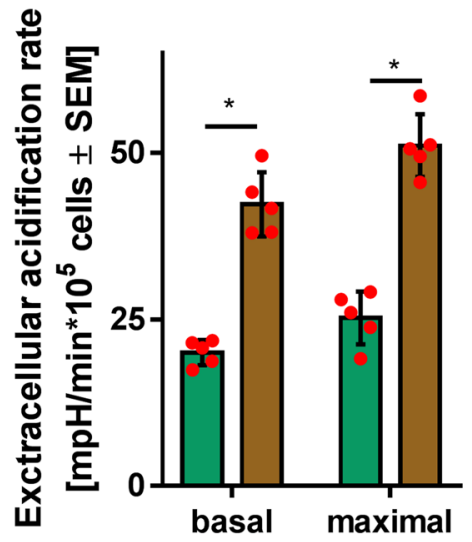

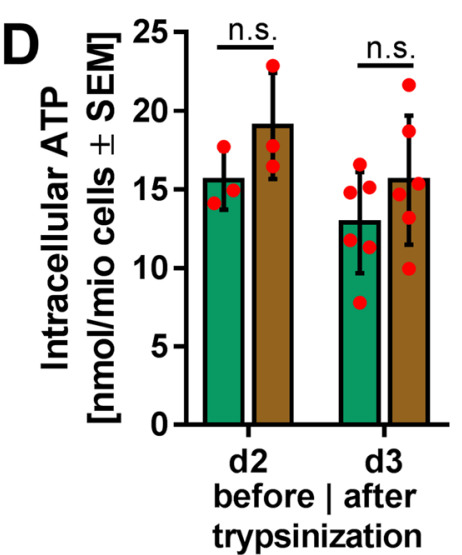

G

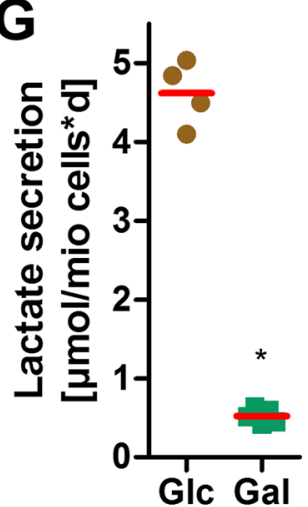

i.e., a metabolite likely to be increased in Gal cells (Yu et al. 2009). Thus, mitochondria are expected to serve as the main source of ATP production in cells cultured in Gal, and this may alter cellular sensitivity to mitochondrial toxicants (Fig. 1e).
To assure that the expected metabolic changes did not alter the overall phenotype, cells cultured in Glc vs Gal were characterized extensively on a morphological and functional level. Major cytoskeletal structures were chosen to characterize cellular morphology and neurite growth qualitatively. 
4Fig. 2 Comparison of basic morphological and metabolic features of cells cultured in glucose vs galactose. a Differentiated (d3) LUHMES cells cultured for $72 \mathrm{~h}$ in either glucose- or galactose-containing medium showed no morphological differences as assessed by staining of nuclei (H-33342) neuronal $\beta$-III-tubulin (Tuj1-antibody) and actin (fluorescent phalloidin). Representative images, image width $625 \mu \mathrm{m}$ in upper row and $185 \mu \mathrm{m}$ in lower row. b The neurite area per life cell was compared for Gal cells vs Glc cells on d2 (directly before trypsinization), or on $\mathrm{d} 3$ ( $24 \mathrm{~h}$ after trypsinization and replating). Differences were tested for statistical significance by two-way ANOVA (sugar $\times$ time), followed by Tukey's post hoc test. Each point represents one biological replicate, n.s. not significant. $\mathbf{c}$ The intracellular contents of the amino acids L-aspartate (Asp) and L-serine (Ser) were measured in Glc and Gal cells. They were normalized to cell count, and then the ratio of the conditions was calculated. Upward bars indicate that the respective metabolite was more abundant in Gal cells. Differences in absolute intracellular amino acid concentrations were tested for statistical significance by two-way ANOVA (sugar $\times$ amino acid), followed by Sidak's post hoc test. Each point represents one biological replicate, ${ }^{*} p<0.05$. d Intracellular ATP was determined in Gal cells and compared to Glc cells, either on d2 (before trypsinization), or on d3 (24 h after trypsinization and replating). Data were normalized to the respective cell numbers. Differences were tested for statistical significance by two-way ANOVA (sugar $\times$ time), followed by Tukey's post hoc test. Each point represents one biological replicate, n.s. not significant. e The oxygen consumption rate, a measure for mitochondrial activity, was determined for $\mathrm{d} 3 \mathrm{Glc}$ and Gal cells. Basal respiration was assessed in untreated cells, while maximal respiration was assessed as described in methods. The respiratory reserve capacity was calculated as the difference between maximal and basal respiration. Differences were tested for statistical significance by unpaired multiple $t$ testing, followed by Sidak-Bonferroni multiple testing correction. Each point represents one biological replicate, $* p<0.05$. $\mathbf{f}$ Extracellular acidification, a measure for glycolytic activity, was determined for $\mathrm{d} 3 \mathrm{Glc}$ and Gal cells. Basal acidification was assessed in untreated cells, while maximal respiration as detailed in methods. Differences were tested for statistical significance by unpaired multiple $t$ testing, followed by Sidak-Bonferroni multiple testing correction. Each point represents one biological replicate, ${ }^{*} p<0.05$. g Lactate secretion by Glc and Gal cells was assessed enzymatically and normalized to cell count. Differences were tested for statistical significance by an unpaired, two-tailed $t$ test, each point represents one biological replicate, ${ }^{*} p<0.05$

No obvious differences were observed for LUHMES cells cultured for $72 \mathrm{~h}$ in Glc or Gal (Fig. 2a). To obtain fully quantitative data, the outgrowth of neurites, on $\mathrm{d} 2$ (before re-seeding) and $\mathrm{d} 3$ (24 h after re-seeding, regular NeuriTox assay endpoint) of cells differentiated in Glc or Gal, was measured. No statistically significant difference between the parallel replicates was found (Fig. 2b). We also evaluated whether the cells adapted their metabolism as expected. Gal cells contained/produced more intracellular aspartate (even to a degree to export it (Suppl. Item 2)), which would support the Mal/Asp shuttle. They also contained less serine, a typical spin-off metabolite from glycolysis. These changes were in accordance with a shift from a glycolytic to a mitochondrial metabolism (Fig. 2c), possibly supported by the use of extracellular Ser from the medium for biosynthetic purposes or glycolysis (Suppl. Item 2).
It was important to verify that the two different metabolic situations both allowed LUHMES cells sufficient ATP production. We found that both cultures had the same intracellular ATP levels (Fig. 2d). To get a more direct measure of differential mitochondrial activity, we measured cellular oxygen consumption rates (indicating mitochondrial activity). As a measure of glycolytic activity, extracellular acidification rates (indicating mainly lactate secretion) were quantified. As expected, the basal respiration was doubled in Gal cells compared to normal Glc cells. Notably, the maximally possible mitochondrial respiration was not significantly affected by the Glc-Gal exchange. The Gal cells exploited their available respiratory chain function to a higher extent, and had accordingly a much lower mitochondrial spare respiratory capacity (Fig. 2e).

Vice versa, the basal glycolytic rate of Gal cells was only about $50 \%$ of that found under Glc conditions. We also tested how far glycolysis could be further accelerated under conditions of maximum demand. In Glc cells, this situation was simulated by inhibition of all residual mitochondrial ATP generation (block by oligomycin). The cells only slightly $(<25 \%)$ increased ECAR under this condition, suggesting that glycolysis was already running maximally. In Gal cells, a maximum pull of Pyr to mitochondria was generated by uncoupling (FCCP). This also did not increase ECAR largely $(<25 \%)$ and it indicated that Gal cells fully used the maximal glycolytic flux possible under the respective Gal supply (Fig. 2f). Finally, the differences in Lac secretion were assessed directly by measurement of extracellular levels of lactic acid over time. The lactate secretion rate of Gal cells was only $14 \%$ of that measured in Glc cells (Fig. $2 \mathrm{~g}$ ).

\section{Increased sensitivity of Gal neurons for toxicity of the complex I inhibitor rotenone}

To test whether the metabolic shift (Glc-Gal) affected the toxicity of mitochondrial inhibitors, the well-established complex I (cI) blocker rotenone was used. Concentration-response data for cell viability were obtained and the Glc-Gal exchange resulted in a drastic shift in sensitivity of neurons to rotenone of about three orders of magnitude (Fig. 3a). Other parameters of cellular function were even more dramatically affected by the sugar exchange. Intracellular ATP levels decreased to $50 \%$ of control at $5 \mathrm{nM}(\mathrm{Gal})$ and at $30 \mu \mathrm{M}$ (Glc), i.e., with a 6000-fold shift (Fig. 3b). Neurite outgrowth (neurite area) also showed a massive shift between Glc and Gal and was in both cases affected at lower concentrations than viability (Fig. 3c). As additional functional parameter, we measured proteasomal activity. In neurons, this cellular function is impaired when mitochondria are dysfunctional and ATP levels drop (Gutbier et al. 2018b; Terron et al. 2018). We found here that proteasome activity was indeed affected in a similar way as ATP levels, with an 
Fig. 3 Increased sensitivity of neurons for toxicity of the complex I inhibitor rotenone. LUHMES cells were differentiated for $48 \mathrm{~h}$ in either glucose (Glc, brown) or galactose (Gal, green) containing medium. After replating, the cells were treated with increasing concentrations of the mitochondrial respiratory chain (MRC) complex I (cI) inhibitor rotenone for $24 \mathrm{~h}$, in the same medium. a The cell viability was assessed by calcein/H-33342 staining. The relative number of live cells (amongst all cells) is indicated. The red arrow indicates the left shift (offset) of the $\mathrm{EC}_{50}$, caused by a switch from Glc to Gal in the assay medium. b-d Different parameters of cellular function were assessed in the same experiment in parallel plates. Vertical lines were included for easier visual comparison. They indicate the concentration of rotenone that reduced ATP levels by $50 \%$. The curves were fitted through the data points derived from five independent experiments. As the concentration spacing was not the same for all experiments, the data points shown are averages from 1 to 5 of these experiments. Different $\mathrm{N}$ numbers for the data points were considered in the fitting procedure. Differences of rotenone-exposed cells vs control were tested for statistical significance by one-way ANOVA, followed by Dunnett's post hoc test. The colored horizontal lines indicate the range of conditions that showed statistically significant effects, $* p<0.05$ (color figure online)

about 1000-fold offset between Glc and Gal cells (Fig. 3d). To separate non-specific toxicants from specific neurotoxicants in the NeuriTox test, the ratio of concentrations affecting neurite outgrowth and viability [e.g., $\mathrm{EC}_{25}(\mathrm{~V}) /$ $\left.\mathrm{EC}_{25}(\mathrm{NA})\right]$ is calculated. If the ratio is $\geq 4$, the toxicant is considered to be a specific neurotoxicant (Delp et al. 2018b; Krug et al. 2013). Under Glc and Gal conditions, rotenone exceeded that threshold strongly (Fig. 4a). The data obtained with rotenone suggest that the Glc-Gal assay can be transferred to LUHMES neurons to detect mitotoxicants more sensitively and to better separate specific neurofunctional effects from plain cytotoxicity.

\section{Effect of a Glc-Gal exchange on neurotoxicity of diverse complex I inhibitors}

To further evaluate the assay for its sensitivity to mitochondrial toxicants, a broader panel of cI inhibitors was tested. We determined for all compounds the $\mathrm{EC}_{25}$ for inhibition of neurite outgrowth $\left(\mathrm{EC}_{25}(\mathrm{NA})\right)$ and for general cell viability $\left(\mathrm{EC}_{25}(\mathrm{~V})\right)$. From these data, we determined the ratio of $\mathrm{EC}_{25}(\mathrm{~V}) / \mathrm{EC}_{25}(\mathrm{NA})$ as measure for specific neurotoxicity. In addition, we visualized for each parameter (V, NA) the shift due to the Glc-Gal exchange. For the five additional inhibitors tested (deguelin, fenazaquin, fenpyroximate, $\mathrm{MPP}^{+}$and pyrimidifen), Gal cells were always much more sensitive for neurite damage than Glc cells (Fig. 4b-f). The same was observed for viability, with exception of $\mathrm{MPP}^{+}$. The cells were not killed by the compound. It was shown earlier that immature LUHMES (d0) are resistant to $\mathrm{MPP}^{+}$(Efremova et al. 2015; Schildknecht et al. 2009), while the system became extremely sensitive after d5 (Krug et al. 2014; Poltl et al. 2012). The cells upregulate the dopamine transporter (DAT), which is required for MPP ${ }^{+}$toxicity, at d2-3 (Scholz
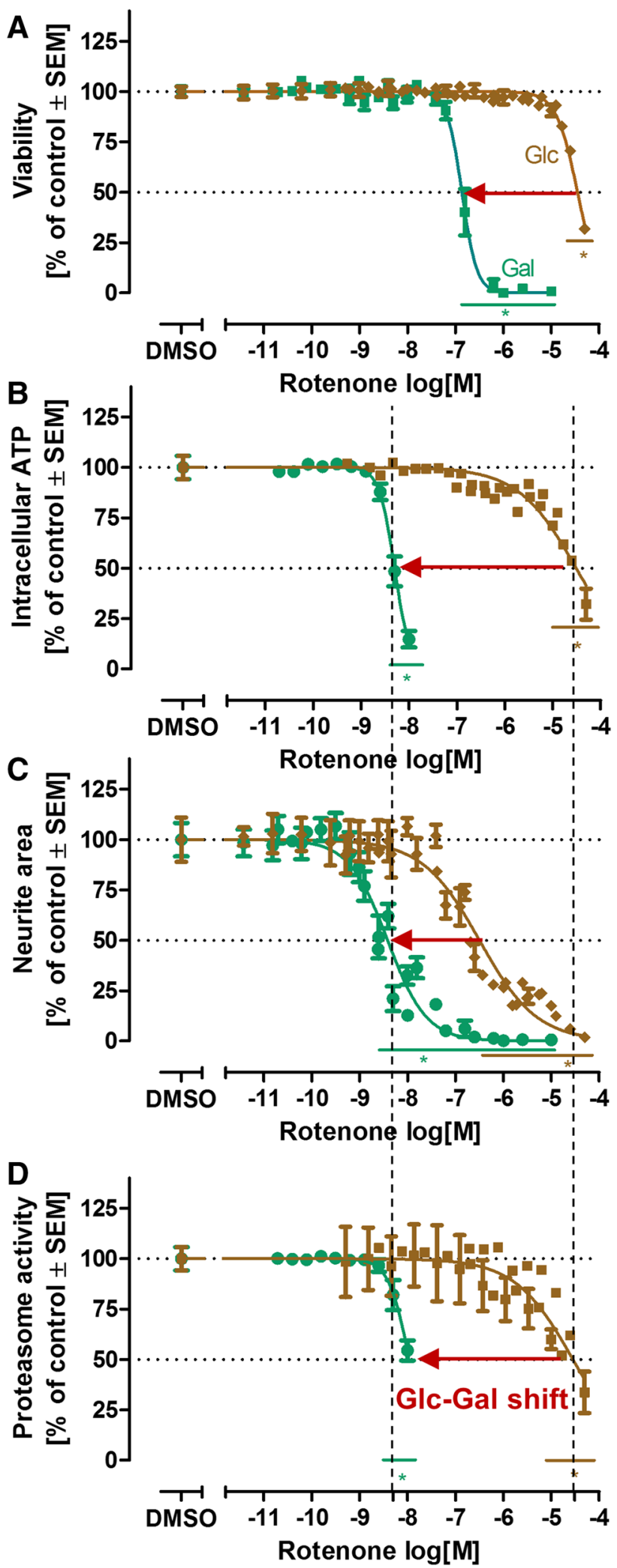

et al. 2011) and the amount of toxicant entry may not be sufficient to kill, but only to affect the more sensitive neurites. For all five compounds, Gal also increased the $\mathrm{EC}_{25}(\mathrm{~V} / \mathrm{NA})$ 
A<smiles>C=C(C)[C@H]1Cc2c(ccc3c2O[C@H]2COc4cc(OC)c(OC)cc4[C@H]2C3=O)O1</smiles>

Rotenone

EC25(V/NA) Glc: 290 EC25(V/NA) Gal: 68

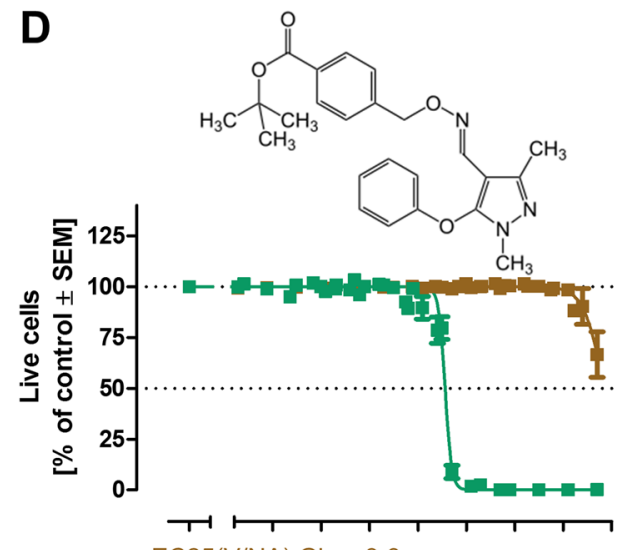

EC25(V/NA) Glc: 3.6

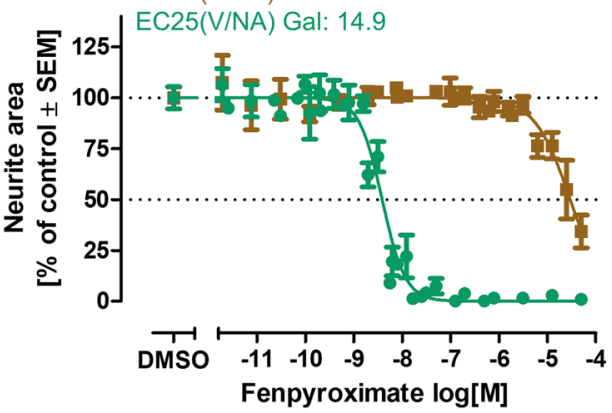

E

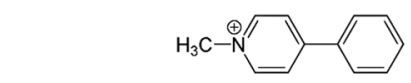

EC25(V/NA) Glc: > 22
C
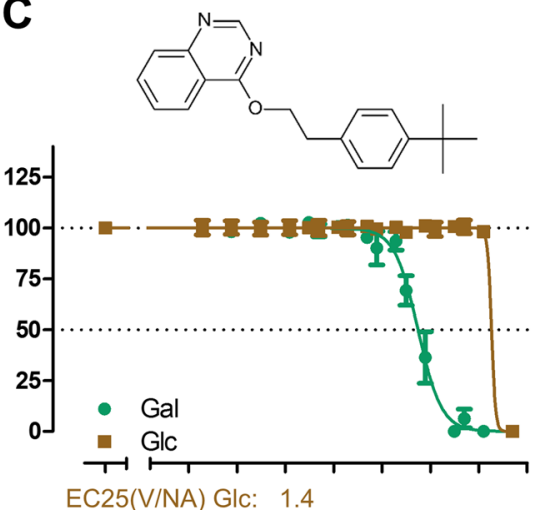

EC25(V/NA) Glc: 1.4

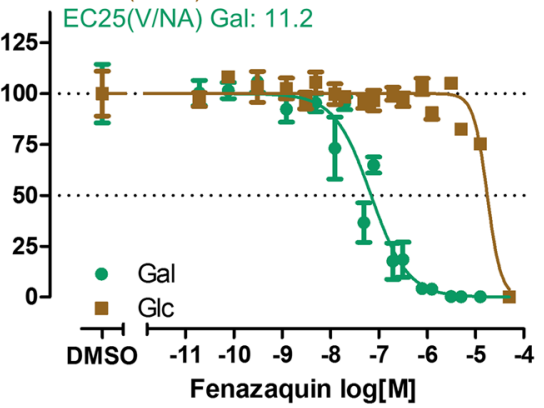

$\mathbf{F}$
Fenazaquin $\log [\mathrm{M}]$
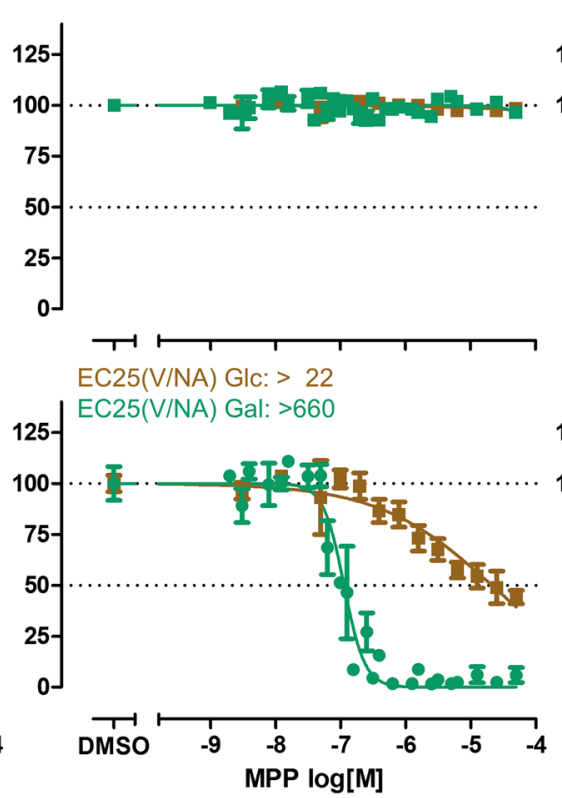<smiles>CCCc1ccc(OCCNc2ncnc(CC)c2Cl)c(C)c1C</smiles>

Fig. 4 Effect of a Glc-Gal exchange on neurotoxicity of diverse complex I inhibitors. A diverse set of mitochondrial respiratory chain (MRC) complex I (cI) inhibitors was tested for neurotoxicity hazard. LUHMES cells were pre-differentiated for $48 \mathrm{~h}$ in either glucose (brown)- or galactose (green)-containing medium and replated on d2. One hour later, the cells were treated with the indicated concentrations of the toxicants for $24 \mathrm{~h}$. a Chemical structure of rotenone and the ratio of $\mathrm{EC}_{25}$ (viability)/EC $\mathrm{EC}_{25}$ (neurite area), i.e., the index for selective neurotoxicity (vs unspecific cytotoxicity) in either Glc or Gal medium. b-f For each compound, the upper graph compares the relative amount of live cells (general viability) for Glc and Gal medium; the lower graph gives the respective data for neurite outgrowth (quantified as neurite area on $\mathrm{d} 3$ ) from the same plates. In between, the neurite specificity ratios are indicated. $\mathrm{EC}_{25}$ values were calculated from a four-parameter Hill function. A measure for $\mathrm{EC}_{25}$ uncertainty was not obtained. The curves were fitted through the data points derived from 3 to 5 independent experiments. As the concentration spacing was adjusted between the experiments, individual data points are from 1 to 5 replicates (color figure online) 

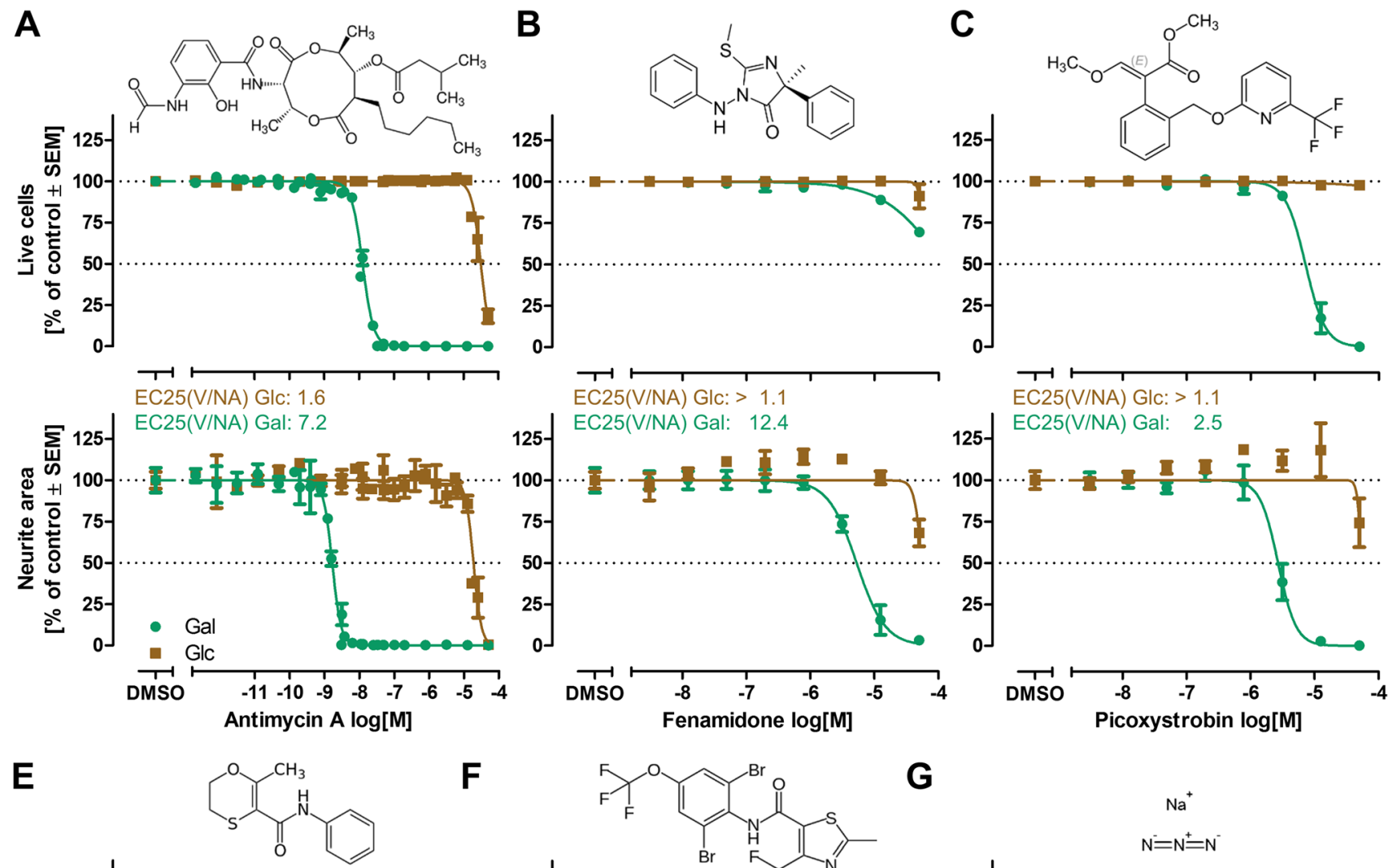

F

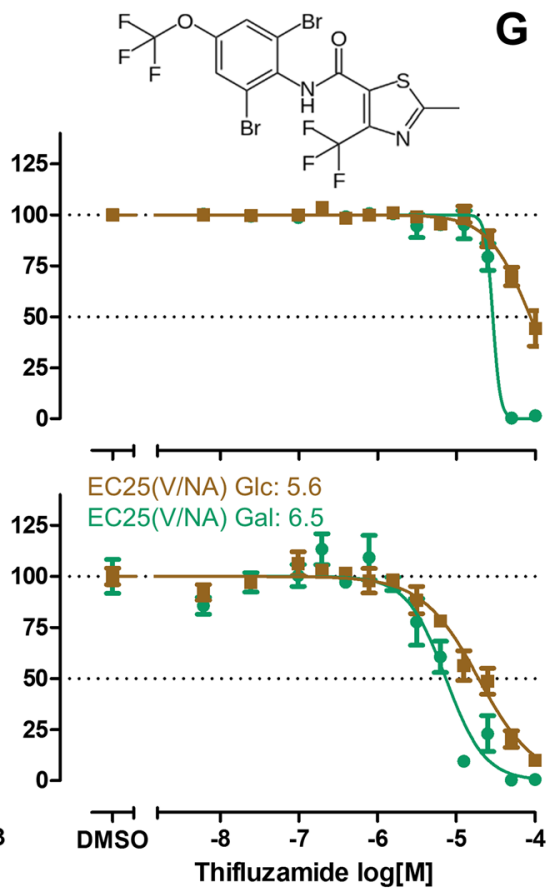

G

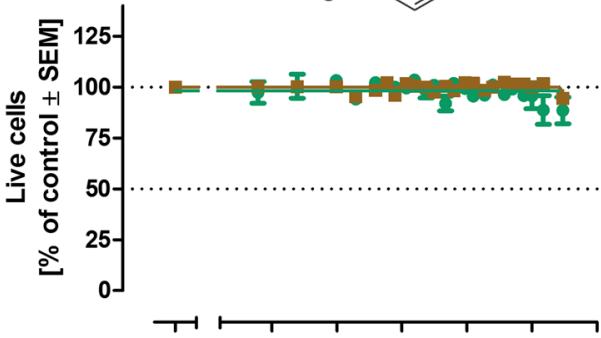

EC25(V/NA) Glc: $>1.9$

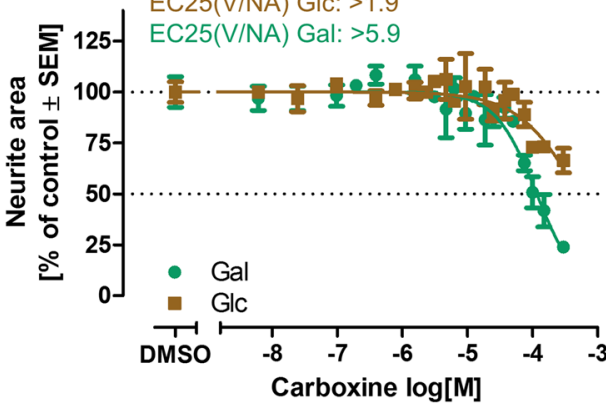

D

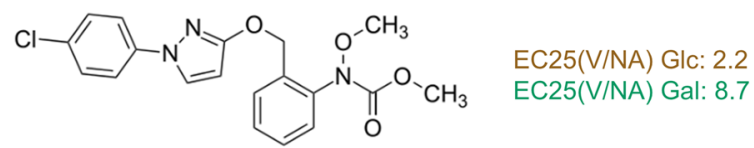

Pyraclostrobin

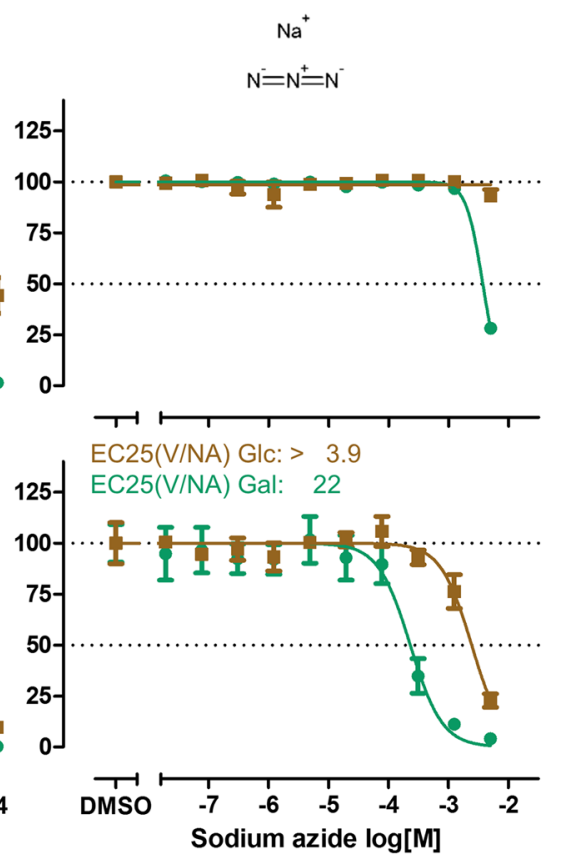

H

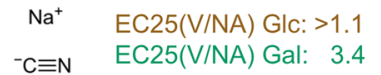

Sodium cyanide 
4Fig. 5 Effect of a Glc-Gal exchange on neurotoxicity of diverse complex II, III and IV inhibitors. A diverse set of mitochondrial respiratory chain (MRC) complex II-IV (cII, cIII, cIV) inhibitors was tested for neurotoxicity hazard. LUHMES cells were pre-differentiated for $48 \mathrm{~h}$ in either glucose- (brown) or galactose (green)-containing medium and replated on $\mathrm{d} 2$. One hour later, the cells were treated with the indicated concentrations of the toxicants for $24 \mathrm{~h}$. For each compound, the upper graph compares the relative amount of live cells (general viability) for Glc and Gal medium; the lower graph gives the respective data for neurite outgrowth (quantified as neurite area on d3) from the same plates. In between, the neurite specificity ratios are indicated. a-d Described cIII inhibitors, e, f described cII inhibitors, $\mathbf{g}$, $\mathbf{h}$ described cIV inhibitors. $\mathrm{EC}_{25}$ values were calculated from a four-parameter Hill function. A measure for $\mathrm{EC}_{25}$ uncertainty was not obtained. The curves were fitted through the data points derived from 3 to 5 independent experiments. As the concentration spacing was different between the experiments, the data points shown are averages from one $1-5$ experiments (color figure online)

ratio compared to the standard NeuriTox assay in Glc. Thus, the encouraging results obtained for rotenone were fully confirmed by the data from other $\mathrm{cI}$ inhibitors.

\section{Effect of a Glc-Gal exchange on neurotoxicity of diverse complex II-V inhibitors, uncouplers and non-mitochondrial toxicants}

Since mitotoxicants might not only affect cI, a set of cII, cIII, cIV and cV inhibitors, as well as uncouplers and nonmitochondrial toxicants was investigated. For cIII inhibitors (antimycin A, fenamidone, picoxystrobin and pyraclostrobin), the Glc-Gal exchange resulted in the same shift of sensitivity as observed with cI inhibitors (Fig. 5a-d), and the $\mathrm{EC}_{25}(\mathrm{~V} / \mathrm{NA})$ ratio increased. Under these conditions (Gal), cIII inhibitors were specific neurotoxicants with the sensitivity of neurites being $\geq 4$ higher than the sensitivity of overall viability.

For few cII inhibitors (carboxine and thifluzamide), Gal increased the sensitivity and neurite specificity, but the offset effects were less drastic. In the presence of Gal, two cII inhibitors became neurite specific (ratio $\geq 4$ ) (Fig. 5e, f). The inhibitor atpenin A5 showed a high specificity in Glc and Gal conditions, but was not more potent in the presence of $\mathrm{Gal}$, and flutolanil was neither enhanced, nor specific at any condition (not shown).

The two investigated cIV inhibitors azide and cyanide also displayed a higher toxicity, if the cells were cultured in $\mathrm{Gal}$ conditions (Fig. 5g, h). For azide, the $\mathrm{EC}_{25}(\mathrm{~V} / \mathrm{NA}$ ) ratio increased to 22 , while cyanide was at best borderline neurotoxic under Gal conditions (ratio 3.4).

The $\mathrm{cV}$ inhibitors also showed a heterogeneous response pattern: Gal cells were more sensitive to 1-octylguanidin and oligomycin than Glc cells, but sensitivity of general cell viability increased stronger then the sensitivity of the neurite outgrowth (Fig. 6a, b). A similar pattern was observed for the two uncoupling substances 2,4-dinitrophenol and
FCCP (Fig. 6c, d). The activity of $\mathrm{cV}$ and the associated tightness of the inner mitochondrial membrane for protons are vital for proper mitochondrial function, but they are not part of the electron transfer process of the MRC. Our results suggest that the core parts of the MRC [cI, cIII, (cIV)] are more affected by Glc-Gal exchange than other mitochondrial functions. Complex II takes a special role, as it belongs to the classical MRC, but is for many metabolic situations rather a minor side entry. Besides the MRC function, it takes its major role as succinate dehydrogenase in the citric acid cycle.

To test the argument that the Glc-Gal shift specifically affects inhibitors of the MRC, we also tested toxicants with non-mitochondrial mode of action. As exemplary toxicants, a proteasome and a Rho kinase pathway inhibitor (bortezomib and narciclasine) were selected and tested. For both substances, the Glc and Gal concentration-response curves were similar (neurite outgrowth as well as viability) (Fig. 6e, f). For bortezomib, which is not a central nervous system neurotoxicant, the low $\mathrm{EC}_{25}(\mathrm{~V} / \mathrm{NA})$ ratio was not significantly affected by Gal. Narciclasine is a specific neurotoxicant (Delp et al. 2018b; Krug et al. 2013), with a large $\mathrm{EC}_{25}(\mathrm{~V} / \mathrm{NA})$ ratio. This was confirmed in the Gal condition.

The results indicate that the Glc-Gal assay can be used to screen substances in medium- to high-throughput screening for potential neurotoxicity and for a liability to affect the MRC. A single operator can handle 20-30 compounds per week to produce concentration-response data. This equals 400-600 data points, assessed in technical triplicates.

Since the LUHMES-based Glc-Gal assay is to our knowledge the first shift assay for neuronal cells, we were interested whether it may be transferred to other neuronal cultures. We chose SH-SY5Y cells, the most frequently used human neuronal cell line in in vitro toxicology as the alternative test system. The cells were differentiated for 5 days in Glc medium and then either kept in Glc until the end of the assay, or they were changed to Gal medium, and allowed to adapt metabolically for $24 \mathrm{~h}$. Subsequently, Glc and $\mathrm{Gal}$ cells were treated for $24 \mathrm{~h}$ with toxicants (from d6 to d7) and thereafter cell viability was measured (Suppl. Item 3A). Three cI (rotenone, deguelin, tebufenpyrad) and two cIII inhibitors (antimycin A and pyraclostrobin) were investigated at a pre-determined concentration $(10 \mu \mathrm{M})$ for their increase in toxicity in Glc vs Gal. These five substances were non-toxic (viability reduction by $<5 \%$ ) in Glc conditions, due to the relatively high tolerance of the neuroblastoma cells to the neurotoxicants (Tong et al. 2017). The exchange to $\mathrm{Gal}$ as main sugar source in the medium, resulted in a significant increase in toxicity, i.e., viability was reduced by 15-35\% of control (Suppl. Item 3B). These preliminary data suggest that the Glc-Gal-shift assay could be transferred to other neuronal test systems. However, it has to be mentioned that LUHMES cells tolerated the Gal conditions much better 
A
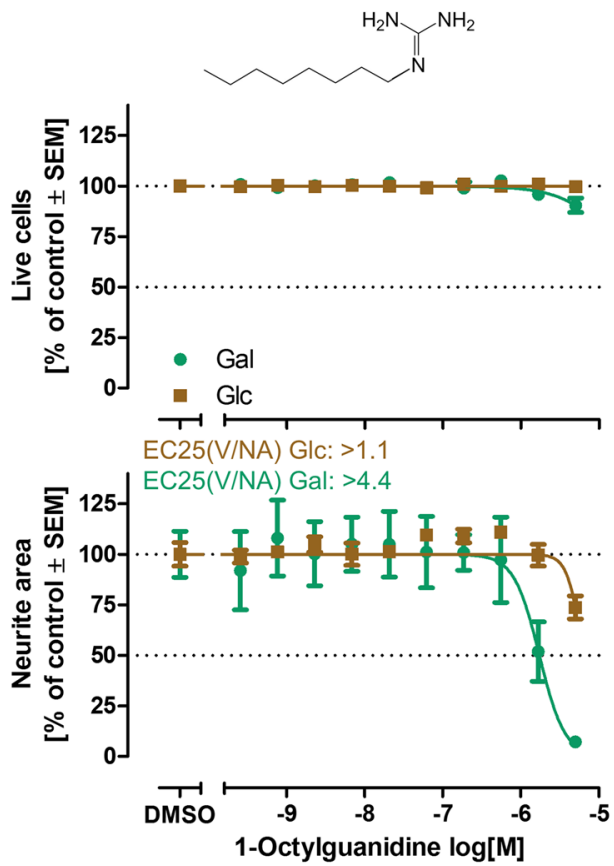

D<smiles>N#CC(=N)Nc1ccc(OC(F)F)cc1</smiles>
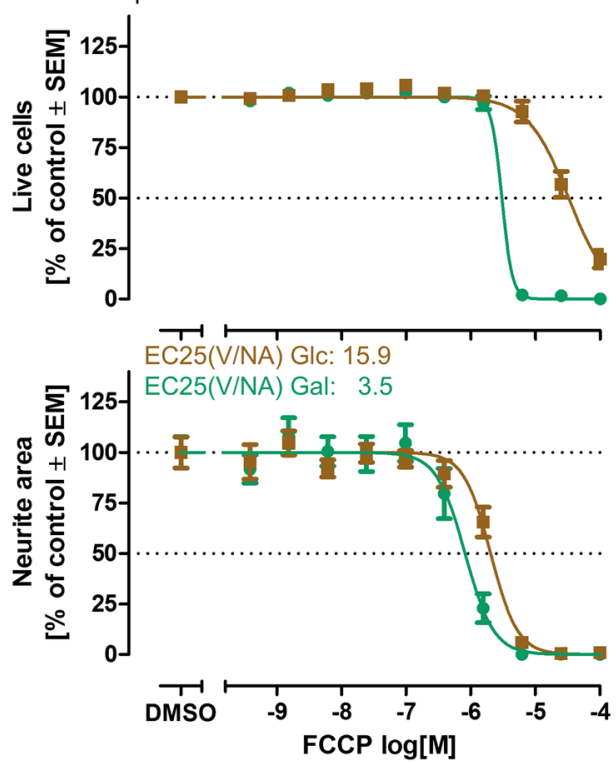

B
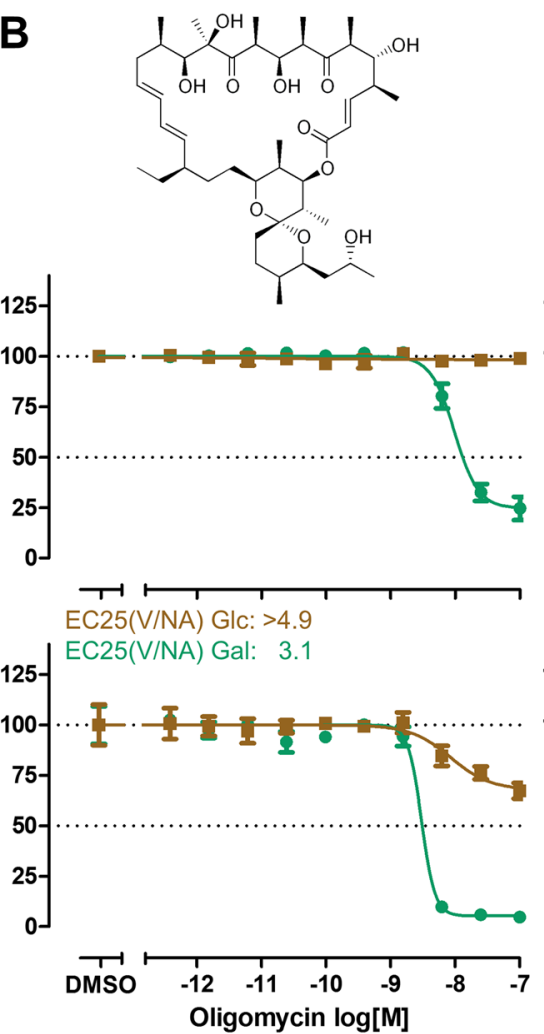

E
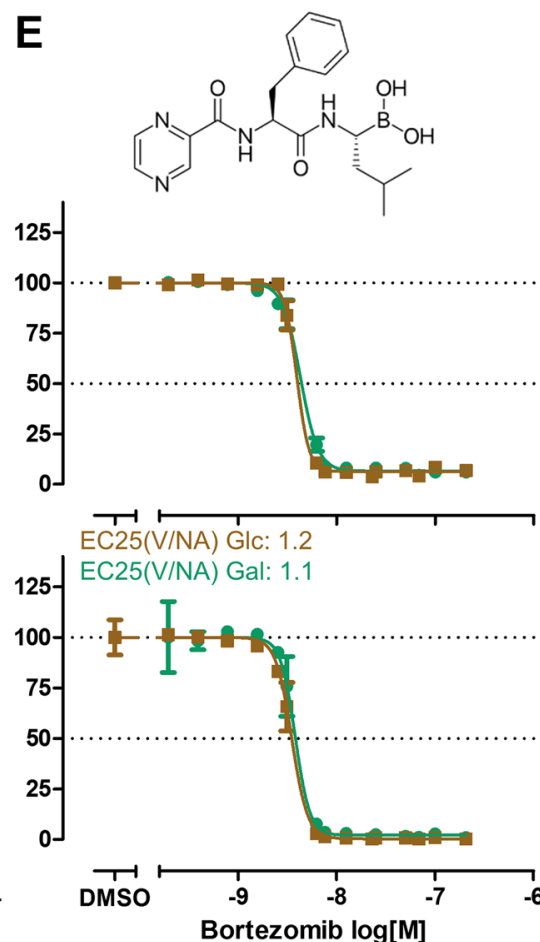

C
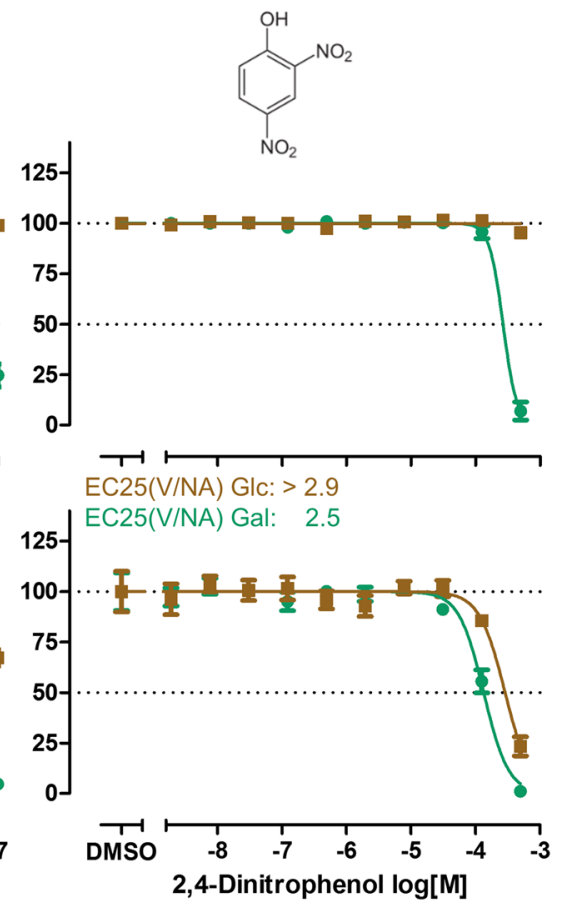

$\mathbf{F}$

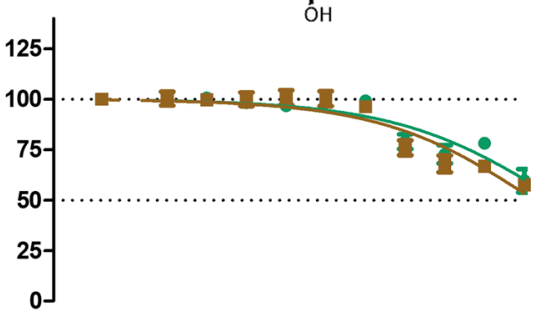

EC25(V/NA') Glc: 41

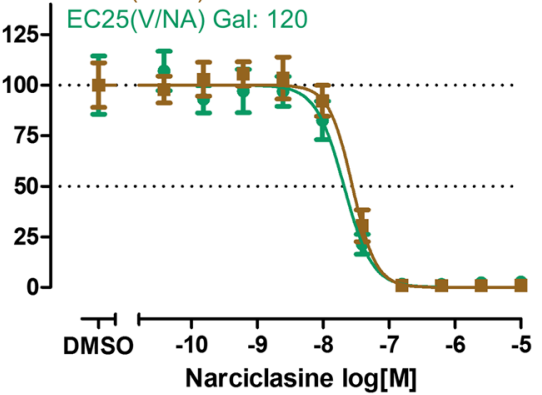

than the SH-SY5Y cells. LUHMES cells could easily be kept in Gal medium for more than 9 days without any increase in cell death compared to Glc conditions (not shown), whereas SH-SY5Y cells poorly tolerated culturing in Gal medium for $>48 \mathrm{~h}$ (fragile neurites, altered morphology; not shown).
This difference in human cell lines could be due to different expression patterns of transporters and enzymes required for Gal metabolism. Alternatively, cells may differ in their ability to increase mitochondrial metabolism in the TCA or MRC, as e.g., the malate/aspartate shuttle may have different 
४Fig. 6 Effect of a Glc-Gal exchange on neurotoxicity of other inhibitors (complex V, uncouplers and non-mitochondrial). A diverse set of mitochondrial respiratory chain (MRC) complex $\mathrm{V}(\mathrm{cV})$ inhibitors, as well as uncoupling substances and non-mitochondrial toxicants was tested for their neurotoxicity hazard. LUHMES cells were predifferentiated for $48 \mathrm{~h}$ in either glucose (brown)- or galactose (green)containing medium and replated on $\mathrm{d} 2$. One hour later, the cells were treated with the indicated concentrations of the toxicants for $24 \mathrm{~h}$. For each compound, the upper graph compared the relative amount of live cells (general viability) for Glc and Gal medium; the lower graph gives the respective data for neurite outgrowth (quantified as neurite area on $\mathrm{d} 3$ ) from the same plates. In between, the neurite specificity ratios are indicated. a, b Described uncouplers, $\mathbf{c}, \mathbf{d}$ described uncouplers, e, f non-mitochondrial toxicants. $\mathrm{EC}_{25}$ values were calculated from a four-parameter Hill function. A measure for $\mathrm{EC}_{25}$ uncertainty was not obtained. The curves were fitted through the data points derived from three independent experiments. As the concentration spacing was adjusted between the experiments, individual data points are from 2 to 3 replicates (color figure online)

limitations. Under sub-optimal metabolic conditions, cells would perceive Gal not as an alternative energy substrate, but as a starvation medium. We conclude that the setup of the Glc-Gal shift assay in other neuronal cells will require careful examination of their metabolic suitability, and fine tuning of the exposure scheme may be necessary to allow clear and robust results.

\section{Confirmation of the mode of action (MoA) of test substances by direct assessment of mitochondrial respiratory chain (MRC) inhibition}

The Glc-Gal NeuriTox assay obviously detected some compounds as potential MRC inhibitors (strong Glc-Gal shift), but a secondary assay with an independent endpoint would be desirable for confirmation of hits, and for exclusion of false positives. Therefore, we used LUHMES cells to implement tests for inhibition of selected mitochondrial targets (Salabei et al. 2014). As a rational for these tests, the following background information is important: (1) eukaryotic cell membranes can be selectively permeabilized (e.g., with digitonin) to deliver respiratory substrates to the mitochondria, without adversely affecting MRC function; (2) selective substrates for each of the MRC complexes I-IV are available; (3) if a more terminal MRC complex (cIII or cIV) of the MRC is directly fed electrons, the respective upstream complexes are not required for oxygen consumption; (4) tool compounds inhibiting cI-IV are available and can be used serially to analyze different mitochondrial functions within one experiment (Fig. 7a).

Based on these conditions, a two-tiered screening approach was developed to identify the mitochondrial target complex for potential neurotoxicants. In the first tier, complex I-III activity was assessed. In brief, specific cI substrates were used to assess cI activity. Subsequently, cI was inhibited and cII substrates were injected. Then, cII was blocked and selective substrates were injected to probe the activity of cIII. In the second tier, cIV was assessed by inhibition of cI and cIII and injection of a cIV substrate (Fig. 7b).

Exemplary data on MRC complex activity of mitochondria treated with highly specific tool compounds indicate the good performance of this test strategy (Fig. 7c). Complex I (rotenone) and cII inhibitors (3-nitropropionic acid) reduced selectively cI and cII activity, while the other complexes were not affected. The cIII inhibitor antimycin A did not affect complex IV activity, and caused a strong cIII inhibition. However, block of the electron flow at cIII lead to an apparent inhibition of cI and cII, since substrates feeding into these complexes could not deliver their electrons to cIV, and thus they did not promote oxygen consumption (Suppl. Item 4). The same was observed for the cIV inhibitor azide which led to an apparent cI-III inhibition. These inhibition patterns, due to the use of OCR as common endpoint for all MRC activity assays, were taken into account for the data evaluation algorithm (Fig. 7d). For the $\mathrm{cV}$ inhibitor oligomycin, which causes an accumulation of protons in the intermembrane space, an apparent inhibition of cI-IV was observed. Inhibition of cI activity was strongest, since electrons fed into the MRC via cI cause most protons to be pumped across the inner mitochondrial membrane ( 5 protons per electron, or 20 protons per $\mathrm{O}_{2}$ finally consumed). Electrons fed into the MRC via cII or cIII cause the translocation of 12 protons per $\mathrm{O}_{2}$ finally consumed, while an electron fed into the MRC via cIV causes the translocation of only 1 proton (4 electrons per $\mathrm{O}_{2}$ consumed). Therefore, the proton gradient-based resistance decreased with proximity to cIV. The uncoupler FCCP did not affect OCR driven by substrates of cII-IV. However, it increased apparent cI activity relative to control. By uncoupling the mitochondrial membrane, the proton gradient physiologically established to allow $\mathrm{cV}$ activity (ATP synthesis) was removed. Thus, cI worked against less resistance when pumping protons across the mitochondrial membrane.

The knowledge about the serial connection of the individual MRC complexes and the typical inhibition patterns of tool compounds lead to the development of a decision model that translates the assay data into a MoA classification (Fig. 7d). Note that the classification model uses the data in a different order than the electron flow through the MRC. This is due to the necessity to take upstream/indirect effects into account.

This screening and decision strategy was applied for 25 compounds to investigate their proposed MoA (Suppl. Item 5). For all described and tested cI inhibitors (7), a selective cI inhibition was confirmed. For four of five cII inhibitors, a selective cII inhibition was confirmed. Mepronil rather behaved like a mixed/cIII inhibitor and the discrepancy with the original literature needs to be clarified (FRAC 2011; Mitani et al. 2001; Zhang et al. 2009). Antimycin A and three strobins were confirmed as cIII inhibitors, while cyazofamid rather displayed 


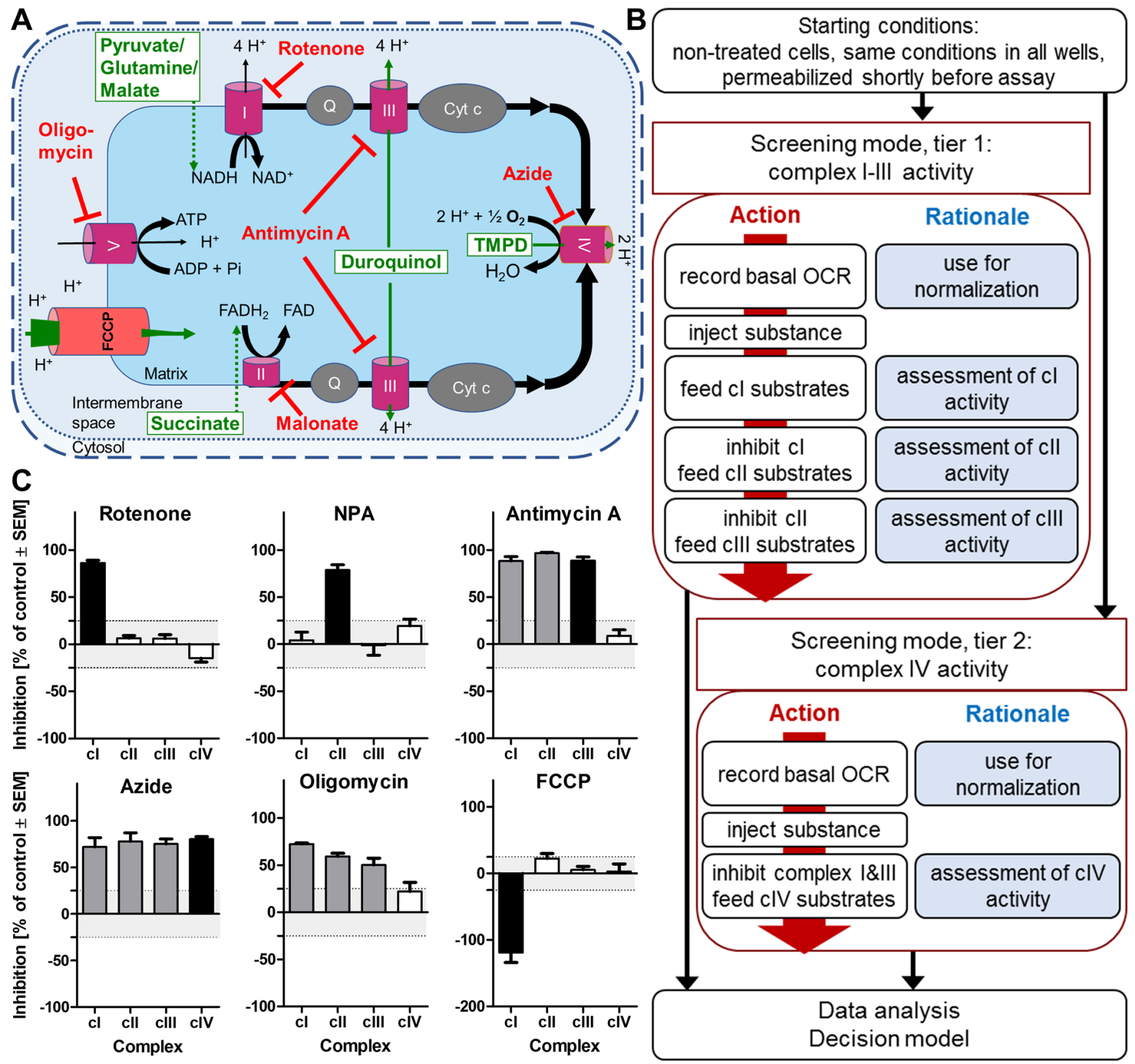

D

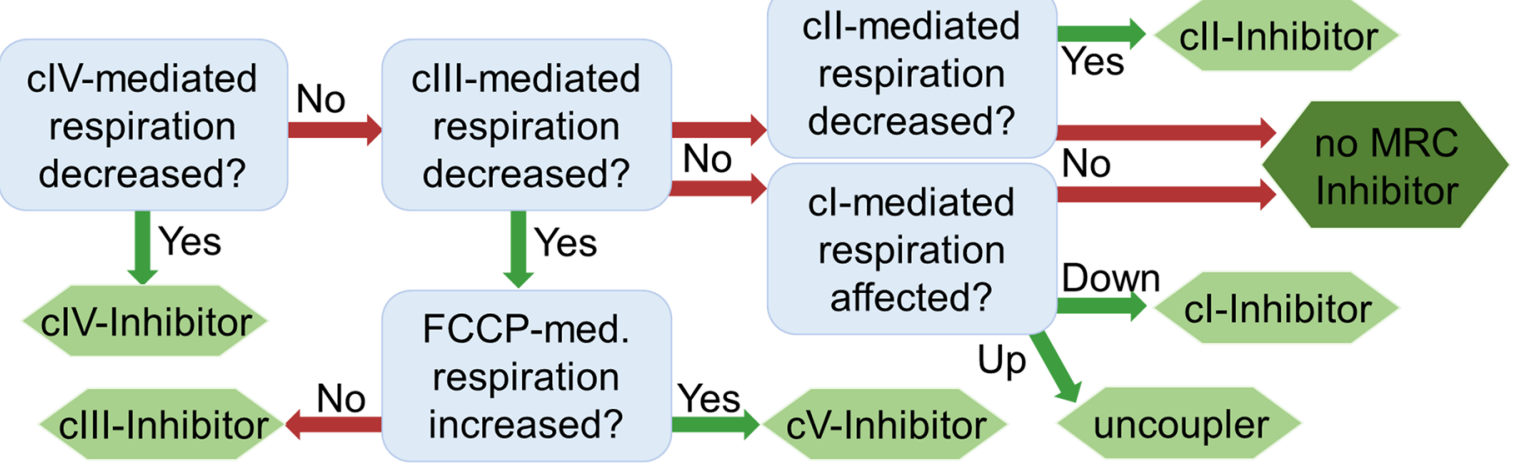

the pattern of an uncoupling substance. Again, differences in the original literature (Dreinert et al. 2018; FRAC 2011; Li et al. 2014) may be due to technical issues, or have a biological basis, as the reference data were obtained with subcellular fractions and/or non-human species. Such model dependence has been observed earlier for, e.g., thiazolidinediones and 
4Fig. 7 Confirmation of the mode of action (MoA) of test substances by direct assessment of mitochondrial respiratory chain (MRC) inhibition. For the assay, cells and their outer mitochondrial membranes (but not the inner mitochondrial membrane) were permeabilized. They were otherwise left intact in the culture dishes. Their oxygen consumption rate (OCR) was measured in the presence of specific substrates and respiration modifiers. a Schematic representation of a mitochondrion within a permeabilized cell. The specific substrates (electron donors) for individual respiratory chain complexes are indicated in green. The complex-specific inhibitors are indicated in red. Individual MRC complexes are displayed as pink barrels. Normally, electrons are fed from NADH into the MRC via cI. They are then transported via ubiquinone/coenzyme Q $(\mathrm{Q})$ to cIII and further on via cytochrome $\mathrm{c}$ (Cyt c) to cIV, which transfers them to the final electron acceptor oxygen $\left(\mathrm{O}_{2}\right)$. The electrons from $\mathrm{FADH}_{2}$ are fed into the MRC via cII, which also transfers them via $\mathrm{Q}$ to cIII. The transport of electrons is coupled to pumping of protons over the inner mitochondria membrane. This proton gradient drives $\mathrm{cV}$, the mitochondrial ATP synthase. FCCP can be used as a tool compound to uncouple the mitochondrial membrane, i.e., to allow a proton flux to the mitochondrial matrix that bypasses $\mathrm{cV}$, and thus does not contribute to ATP generation. b Workflow and rationale to screen for inhibitory effects of toxicants on individual MRC complexes, using the Agilent Seahorse XF analyzer for quantification of the OCR. Cells were permeabilized manually before they were placed into the Seahorse analyzer. Then the basal OCR was assessed, and used for internal normalization (cell number/activity correction) between the wells. Then, the potential toxicant was injected and one of two screen programs (denominated here tier1/tier2) was run. In tier 1 , first cI activity was assessed. Subsequently, cI was inhibited and a selective substrate of cII was added (cII feeding). Further on, cII was inhibited and a selective substrate of cIII was added (cIII feeding). In tier 2, the complex IV activity was assessed. For this, cI and cIII were inhibited and cIV was fed. All toxicant data were compared to solvent control (DMSO) and were, after normalization, analyzed applying the decision model depicted in d. c Exemplary data sets for six wellestablished tool compounds to demonstrate the typical assay performance. White bars indicate non-significant effects on the respective complex. Black bars indicate the main inhibited complex; gray bars indicate that the respiration via the respective complex was significantly reduced, but this effect was assumed to be secondary/indirect due to the sequential assay conditions shown in b. The light gray area indicates the non-significant range of the assay, and was defined by $\times 2$ SD of the baseline variation. The error bars for the complex inhibition by the compounds are the SEM of $\geq 3$ independent replicates (NPA: 3-nitropropionic acid). d Decision model translating the results of the screen (blue boxes) as described in b into a compound classification (green hexagons). Note that the experimental scheme (sequence of measurements) differs from the data evaluation scheme! The latter decision tree starts with the evaluation of cIV data. If cIVmediated respiration was impaired (measured in tier 2), the substance was classified as cIV inhibitor. If not, data on cIII-mediated respiration were used. If they showed cIII to be impaired, then additional data on the effect of FCCP were required. If FCCP increased the cIIImediated respiration, the test substance was classified as $\mathrm{cV}$ inhibitor, while it was classified to be a cIII inhibitor, if cIII-mediated OCR was not affected by FCCP addition. Note that the variant of tier $1 \pm$ FCCP is not shown in B) for clarity reasons. If cIII-mediated respiration was not affected, data on cII- and cI-mediated respiration were used. If data indicated that cII-mediated respiration was reduced, the compound was classified as cII inhibitor. If cI-mediated respiration was increased by the toxicant, it was classified as an uncoupler; if it was decreased, the toxicant was classified as cI inhibitor. If neither cI nor cII activity was affected (and also not cIII and IV, as determined earlier), the substance was classified as "no MRC inhibitor" (color figure online) statins, which either inhibit several mitochondrial complexes or/and uncouple the respiratory chain (Nadanaciva et al. 2007). Moreover, uncouplers like FCCP are known to lead to MRC inhibition when used at too high concentrations (Senkowski et al. 2015).

Substances not described as MRC inhibitors (e.g., colchicine or carbaryl) were clearly classified as such (non-MRC inhibitors). Interestingly, one substance (dhmtAc, ID\#14) identified earlier by us as chemotherapeutic with potential neurotoxic side effects (de Souza-Fagundes et al. 2018), was found to cause a mixed cI/cIII inhibition, and thus to act as typical mitotoxic neurotoxicant.

\section{Enhanced detection of neurotoxicants by the Glc- Gal shift NeuriTox assay}

To determine the assay performance of the Glc-Gal shift assay, the training set was expanded to a total of $n=53$ (adjust) substances. They represented different types of mitochondrial and non-mitochondrial toxicant classes (Fig. 8a, Suppl. Item 1). While specific cIV inhibitors were hard to find, many compounds have been described earlier to block cI and cIII. Several of these have been optimized for pesticide use (Becker et al. 1981; FRAC 2011; Lümmen 1998; Nauen and Bretschneider 2002; Sherer et al. 2007). Our classification of these compounds is based on their original description or review literature on this. In this context, it is important to note that the uncertainties of classification differ from toxicant to toxicant. Substances like rotenone have a high specificity and have been used and confirmed in dozens of studies, while descriptions of other compounds may date back many decades, and data on the specificity of a mode of action (as opposed to other ones) are hard to determine. In a synoptic overview, the literaturebased classification was displayed together with information on confirmed mechanisms in the MRC complex assay for a subset of compounds (Fig. 8b).

To identify the substances to which cells were more sensitive in the Gal conditions, the $\mathrm{EC}_{25}(\mathrm{NA})$ [Glc/Gal] ratio was calculated and color coded. Further on, as measure for specific neurotoxicity, the $\mathrm{EC}_{25}(\mathrm{~V} / \mathrm{NA})$ ratio was calculated for both, the Glc and Gal conditions. For many of the tested cI-cIV inhibitors, the specificity ratio increased in Gal medium. For uncouplers and non-mitochondrial toxicants of all modes of action (e.g., cytoskeleton interfering, proteasome inhibitors, endoplasmic reticulum stressors, and DNA damaging agents), the ratios were hardly affected (Fig. 8b, c).

Assessing the Glc vs Gal offset in more detail, it gets obvious that Gal cells had clearly increased sensitivities to all tested cI inhibitors (median offset of 450) and clearly no increased sensitivity to all tested non-mitochondrial toxicants (median offset ratio of 1.0) (Fig. 8d). Inhibitors for 


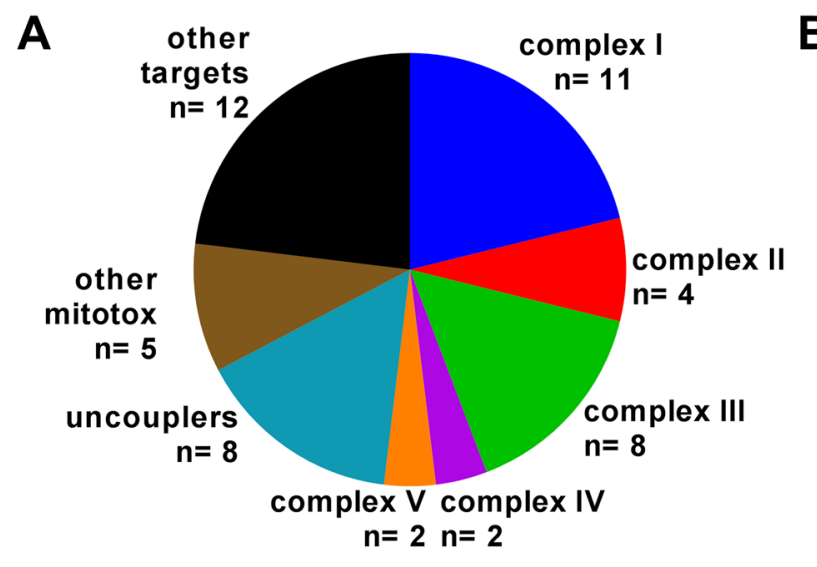

\begin{tabular}{|c|c|c|c|c|}
\hline MoA & Substance & $\begin{array}{l}\mathrm{EC}_{25}(\mathrm{NA}) \\
{[\mathrm{GIc} / \mathrm{Gal}]}\end{array}$ & $\begin{array}{l}\mathrm{EC}_{25}(\mathrm{~V} / \mathrm{NA}) \\
{[\mathrm{Gal}]}\end{array}$ & $\begin{array}{l}\mathrm{EC}_{25}(\mathrm{~V} / \mathrm{NA}) \\
{[\mathrm{GIc}]}\end{array}$ \\
\hline \multirow{11}{*}{$\overline{0}$} & Berberine & 7 & 24 & $>5.7$ \\
\hline & Deguelin & 450 & 28 & 9.4 \\
\hline & Fenazaquin & 450 & 11 & 1.4 \\
\hline & Fenpyroximate & 5600 & 15 & 3.6 \\
\hline & MPP & 30 & $>660$ & $>22$ \\
\hline & Nefazodone & 10 & 5.4 & 2.2 \\
\hline & Phenformin & 27 & $>77$ & $>2.9$ \\
\hline & Pyridaben & 75000 & 81 & $>1.7$ \\
\hline & Pyrimidifen & 10000 & 18.0 & 1.4 \\
\hline & Rotenone & 51 & 68 & 290 \\
\hline & Tebufenpyrad & 2700 & 61 & 1.1 \\
\hline \multirow{4}{*}{$=$} & Atpenin A5 & 1.2 & $>190$ & $>150$ \\
\hline & Carboxine & 3.1 & $>5.9$ & $>1.9$ \\
\hline & Flutolanil & 0.9 & $>1.1$ & $>1.4$ \\
\hline & Thifluzamide & 2.0 & 6.5 & 5.6 \\
\hline \multirow{8}{*}{$\equiv$} & Antimycin $\mathrm{A}$ & 12000 & 7.2 & 1.6 \\
\hline & Azoxystrobin & 3.6 & 10 & $>7.6$ \\
\hline & Fenamidone & 16 & 12 & $>1.1$ \\
\hline & Hydramethylnon & 1.0 & 0.6 & 0.6 \\
\hline & Kresoxim-methyl & 9.9 & 3.2 & $>1.0$ \\
\hline & Picoxystrobin & 26 & 2.5 & $>1.1$ \\
\hline & Pyraclostrobin & 150 & 8.7 & 2.2 \\
\hline & Trifloxistrobin & 18 & 1.8 & $>1$ \\
\hline \multirow{2}{*}{$\underset{0}{\geq}$} & Sodium azide & 11 & 22 & $>3.9$ \\
\hline & Sodium cyanide & 5.2 & 3.4 & $>1.1$ \\
\hline \multirow{2}{*}{3} & 1-Octylguanidine & 4.3 & $>4.4$ & $>1.1$ \\
\hline & Oligomycin & 8.7 & 3.1 & $>4.9$ \\
\hline \multirow{8}{*}{ 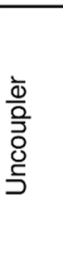 } & 2,4-Dinitrophenol & 2.1 & 2.4 & $>2.9$ \\
\hline & FCCP & 2.5 & 3.5 & 16 \\
\hline & CCCP & 1.2 & 3.7 & 10 \\
\hline & Hexachlorophene & 1.6 & 1.7 & 1.4 \\
\hline & BAM-15 & 1.4 & 2.3 & 2.1 \\
\hline & Niclosamide & 1.4 & 3.1 & 3.6 \\
\hline & Salinomycin & 3.7 & 14 & 9.7 \\
\hline & Valinomycin & 1.0 & 23 & 9.4 \\
\hline \multirow{5}{*}{ 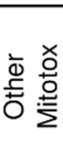 } & Mepronil & 1.2 & 3.3 & 3.5 \\
\hline & Phenyolglyoxal & 1.3 & 2.9 & 5.5 \\
\hline & Triphenyltinhydroxide & 0.9 & 1.4 & 4.6 \\
\hline & MTPB & 8.6 & 26 & 4.4 \\
\hline & UK5099 & 1.7 & 5.7 & 2.4 \\
\hline \multirow{12}{*}{ 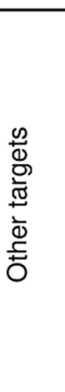 } & Colchicine & 0.5 & $>1100$ & $>2300$ \\
\hline & Diethylstilbestrol & 1.0 & 3.8 & 3.5 \\
\hline & MG-132 & 1.4 & 1.1 & 1.1 \\
\hline & Narciclasine & 1.5 & 120 & 41 \\
\hline & Bortezomib & 0.9 & 1.1 & 1.2 \\
\hline & Cytochalasin D & 1.5 & 5.9 & $>4.6$ \\
\hline & Albendazol & 1.0 & $>100$ & $>110$ \\
\hline & Bromopyruvate & 1.0 & 1.2 & 1.2 \\
\hline & Methyl mercury & 1.1 & 1.1 & 1.3 \\
\hline & Cisplatin & 1.0 & 1.6 & 2.8 \\
\hline & Doxorubicin & 0.5 & 3.6 & 2.3 \\
\hline & Brefeldin A & 0.7 & $>490$ & $>690$ \\
\hline
\end{tabular}

cIII and cIV had median offset ratios of 17 and 8.1, while other toxicants showed largely similar effects in Glc and Gal medium.

A clear alert for neurotoxicity was also given for valinomycin and salinomycin. Both compounds are described to be selective potassium ionophores (Daniele and Holian 1976; Furlong et al. 1998; Mitani et al. 1975; Naujokat et al. 2010). This provides a plausible MoA: under physiological conditions, the proton motive force ( $\Delta \mathrm{p}$, Gibb's free energy) across the inner mitochondrial membrane, is due to: (1) the

concentration gradient of $\mathrm{H}^{+}(\Delta \mathrm{pH})$ and (2) the mitochondrial membrane potential $(\Delta \Psi)$. A free potassium transport across the mitochondrial membranes (caused by valinomycin) eliminates $\Delta \Psi$, while $\Delta \mathrm{pH}$ is not affected directly. Thus, potassium ionophores decrease $\Delta p$, but do not completely eliminate it (different from classical uncouplers). Since respiration of intact cells was increased after valinomycin treatment (not shown), these two compounds were classified as uncouplers, although their MoA differs from classic $\mathrm{H}^{+}$ionophore uncouplers. The specificity ratio was increased for valinomycin and 
४Fig. 8 Synoptic overview of tested substances and their enhancement of neurotoxicity by a Glc-Gal shift. a Overview of all tested substances $(n=52)$ in the Glc-Gal-NeuriTox assay, grouped according to their assumed mode of action (MoA). b Detailed tabular overview about the tested substances, their toxic potency and their selective neurotoxicity data (ratios of concentrations that impaired neurite outgrowth and viability) in Glc vs Gal media. The column with the ratio of $\mathrm{EC}_{25}(\mathrm{NA})[\mathrm{Glc} / \mathrm{Gal}]$ informs about the increase in sensitivity when the cells were cultured in galactose. In this column, cells were marked red if the ratio was $<1.5$ (no enhancement by Gal), yellow if it was between 1.5 , and 3 and green, if it was $>3$ (strong toxicity enhancement by Gal). The two columns to the right indicate the ratio between the concentrations that caused specific neurite outgrowth inhibition (NA) and unspecific cell death (V). The cells in this column were colored blue, if the ratio was $\geq 4$. Such compounds were considered to be specific neurotoxicants. Small superscripts on the compound names indicated results from our mitochondrial complex activity profiling; cI-cIV indicate a classification as inhibitor of $\mathrm{cI}-\mathrm{V}, \mathrm{u}$ indicates uncoupling, $\mathrm{m}$ indicates a mixed impairment of the MRC, o indicates that the substance did not interfere with cI-V activity. Cyazofamid was not included in this analysis since it was insoluble in the active concentration range. $\mathbf{c}$ Enhancement in neurotoxicity (=impairment of neurite outgrowth; NA) in Glc (brown) vs $\mathrm{Gal}$ (green) cells is displayed for all test compounds, subdivided by their assumed mode of action. The black lines indicate an enhanced neurotoxicity under Gal conditions if they are angled upwards. $\mathbf{d}$ The data from $\mathrm{C}$ are indicated as ratio of Glc (brown)/Gal (green) data points, i.e., the enhancement by Gal vs Glc is directly visualized. The red horizontal lines indicate the median enhancement within the group of compounds, e.g., about 450-fold for the group of cI inhibitors. Median values for cII-V inhibitors, uncoupling and non-mitochondrial toxicants are $1.6,17,8.1,6.5,1.5,1.0$, respectively. $M T P B$ methyltriphenylphosphonium bromide (color figure online)

salinomycin in Gal medium, confirming the neurotoxicity of these compounds. Sensitivity of the cells to the proton ionophores CCCP and FCCP, which both rescind the proton $(\Delta \mathrm{pH})$ and charge $(\Delta \Psi)$ gradients, was slightly increased in Gal conditions. However, the $\mathrm{EC}_{25}(\mathrm{~V} / \mathrm{NA})$ ratio was decreased for both uncouplers from $\geq 4$ in Glc to $<4$ in Gal. The comprehensive understanding of potential organ (CNS)-specific toxicities of such compounds will require further studies.

Among the tested cIII inhibitors, hydramethylnon was the only one, for which no sensitivity offset between Glc and Gal conditions was observed. Moreover, its $\mathrm{EC}_{25}(\mathrm{~V} / \mathrm{NA})$ ratio was the lowest of all measured cIII inhibitors. Viability and neurite outgrowth curves were overlapping and extremely steep, which made it technically difficult to quantify small changes robustly, and other (non-mitochondrial) MoA cannot be excluded for this compound.

\section{Conclusions and outlook}

\section{Detection and evaluation of neurotoxicity and mitotoxicity}

In this study, we evaluated the feasibility and usefulness of tuning the established NeuriTox assay to detect mitochondrial neurotoxicants more sensitively. Culture in galactose-containing medium made LUHMES cells metabolically more reliant on mitochondrial metabolism.

The a priori effect of Gal on toxicant sensitivity is assumed to be due to a higher dependence of cells on MRC function (Marroquin et al. 2007). Although our data are largely consistent with this (Suppl. Items 6,7), detailed mechanistic follow up seems important for two reasons: (1) the data do not allow conclusions on whether 'mitochondrial function' refers only to ATP synthesis, or whether other processes, such as mitochondrial ROS generation (Indo et al. 2007) are also involved; (2) the exact analysis of concentration-response curves suggests that cell function (neurite outgrowth) may be affected at inhibitor concentrations not affecting ATP levels (Suppl. Item 6).

Besides galactose, other carbohydrates and metabolic modifiers have been used for metabolic reprogramming of cells. It is important to note that nearly all of them show cell type-specific effects, as they depend on the expression patterns of specific enzymes as well as specific metabolic need of the respective cells. For instance, fructose can be used to shift the cell death program from apoptosis to necrosis in hepatocytes, or to protect the liver from TNF toxicity in vivo (Latta et al. 2000). It acts by depleting cellular phosphate (and therefore ATP), similarly to the frequently used sugar analogue deoxyglucose (Pietzke et al. 2014). Mannose acts on certain tumor cells by impairment of glycolysis and increases the cytotoxic effects of chemotherapy without affecting cellular ATP levels (Gonzalez et al. 2018).

Other metabolic modifiers that drastically affect cellular apoptosis/necrosis are, e.g., nitric oxide (Leist et al. 1999; Volbracht et al. 1999) or the amino sugar galactosamine (Gantner et al. 1995; Leist et al. 1995). Also here, cell specificities are observed due to the metabolic machinery expressed. Our study shows that LUHMES cells, at the developmental stage used for the NeuriTox test, ideally fulfill the requirements for a Glc-Gal shift assay: (1) they can use Gal as energy substrate (and survive up to 9 days in it), and (2) they are metabolically re-programmed by Gal to increase mitochondrial contribution to ATP generation.

This allowed a more sensitive identification of neurotoxicants and mitochondrial toxicants. While the former are identified by a ratio of $\mathrm{EC}_{25}(\mathrm{~V}) / \mathrm{EC}_{25}(\mathrm{NA}) \geq 4$, the latter can be identified by an increased sensitivity in Gal conditions vs Glc conditions [shift in $\mathrm{EC}_{25}(\mathrm{NA})$ ]. If the threshold for that shift is set to two, mitochondrial toxicants are identified with a sensitivity of $89 \%$ (for cI-V inhibitors and non-mitochondrial toxicants; $n=39$ ). Toxicants with a MoA that is not primarily related to mitochondrial metabolism showed no shift in sensitivity in Glc 
vs $\mathrm{Gal}$ conditions. The test specificity was in this case $100 \%$ for non-mitochondrial substances. This was regardless of the fact whether these substances were considered to be neurotoxic (e.g., colchicine, narciclasine, brefeldin, albendazole) or unspecifically cytotoxic (e.g. MG-132, cisplatin).

A major challenge in the field of mitotoxicity remains the exact definition and mechanistic understanding of processes leading to "mitochondrial toxicity". The Glc-Gal-shift assays as tool to identify neuronal MRC inhibitors has been successfully applied here for a neuronal culture. Although the new test has proven to be valuable already, important questions remain with respect to a broader characterization of diverse mitochondrial dysfunctions, e.g., triggered by inhibitors of fatty acid oxidation, mitochondrial DNA synthesis, the urea cycle or phospholipid and steroid synthesis.

Our finding that toxicity to $\mathrm{cI}$ inhibitors was extremely affected by the Glc-Gal shift, while cells were hardly sensitized to cII inhibitors, shows that these MRC complexes must take fundamentally different physiological roles and thus cause different toxicities. This deserves further attention, e.g., in the context of AOP development, where the key event "mitochondrial dysfunction" (Terron et al. 2018) may need to be defined in more detail.

Acknowledgements This work was supported by the Land-BW (INVITE, NEURODEG), the BMBF (e:ToP program, NeuriTox), UKN/DFG (KoRS-CB) and the Projects from the European Union's Horizon 2020 research and innovation programme EU-ToxRisk (grant agreement No 681002) and ENDpoiNTs (grant agreement No 825759). We thank Dr. Philipp Secker for fruitful discussions about the mitochondrial complex activity assay.

\section{Compliance with ethical standards}

Conflict of interest Authors declare that they have no conflict of interest.

Open Access This article is distributed under the terms of the Creative Commons Attribution 4.0 International License (http://creativeco mmons.org/licenses/by/4.0/), which permits unrestricted use, distribution, and reproduction in any medium, provided you give appropriate credit to the original author(s) and the source, provide a link to the Creative Commons license, and indicate if changes were made.

\section{References}

Aleo MD, Luo Y, Swiss R, Bonin PD, Potter DM, Will Y (2014) Human drug-induced liver injury severity is highly associated with dual inhibition of liver mitochondrial function and bile salt export pump. Hepatology (Baltimore, MD) 60(3):1015-1022. https://doi.org/10.1002/hep.27206

Arroyo JD, Jourdain AA, Calvo SE et al (2016) A Genome-wide CRISPR death screen identifies genes essential for oxidative phosphorylation. Cell Metab 24(6):875-885. https://doi. org/10.1016/j.cmet.2016.08.017
Attene-Ramos MS, Huang R, Michael S et al (2015) Profiling of the Tox 21 chemical collection for mitochondrial function to identify compounds that acutely decrease mitochondrial membrane potential. Environ Health Perspect 123(1):49-56. https://doi. org/10.1289/ehp. 1408642

Bal-Price A, Crofton KM, Leist M et al (2015a) International STakeholder NETwork (ISTNET): creating a developmental neurotoxicity (DNT) testing road map for regulatory purposes. Arch Toxicol 89(2):269-287. https://doi.org/10.1007/s00204-015-1464-2

Bal-Price A, Crofton KM, Sachana M et al (2015b) Putative adverse outcome pathways relevant to neurotoxicity. Crit Rev Toxicol 45(1):83-91. https://doi.org/10.3109/10408444.2014.981331

Bal-Price A, Leist M, Schildknecht S, Tschudi-Monnet F, Paini A, Terron A (2018) Adverse outcome pathway on inhibition of the mitochondrial complex I of nigro-striatal neurons leading to parkinsonian motor deficits. OECD Publishing, Paris. https://doi. org/10.1787/b46c3c00-en

Barbosa DJ, Capela JP, de Lourdes Bastos M, Carvalho F (2015) In vitro models for neurotoxicology research. Toxicol Res 4(4):801-842. https://doi.org/10.1039/C4TX00043A

Becker WF, Von Jagow G, Anke T, Steglich W (1981) Oudemansin, strobilurin A, strobilurin B and myxothiazol: new inhibitors of the bc 1 segment of the respiratory chain with an E- $\beta$-methoxyacrylate system as common structural element. FEBS Lett 132(2):329-333. https://doi.org/10.1016/00145793(81)81190-8

Begriche K, Massart J, Robin MA, Borgne-Sanchez A, Fromenty B (2011) Drug-induced toxicity on mitochondria and lipid metabolism: mechanistic diversity and deleterious consequences for the liver. J Hepatol 54(4):773-794. https://doi.org/10.1016/j. jhep.2010.11.006

Blomme EA, Will Y (2016) Toxicology strategies for drug discovery: present and future. Chem Res Toxicol 29(4):473-504. https:// doi.org/10.1021/acs.chemrestox.5b00407

Budnitz DS, Pollock DA, Weidenbach KN, Mendelsohn AB, Schroeder TJ, Annest JL (2006) National surveillance of emergency department visits for outpatient adverse drug events. JAMA 296(15):1858-1866. https://doi.org/10.1001/jama.296.15.1858

Daniele RP, Holian SK (1976) A potassium ionophore (valinomycin) inhibits lymphocyte proliferation by its effects on the cell membrane. Proc Natl Acad Sci 73(10):3599-3602. https://doi. org/10.1073/pnas.73.10.3599

de Souza-Fagundes EM, Delp J, Prazeres PDM et al (2018) Correlation of structural features of novel 1,2,3-triazoles with their neurotoxic and tumoricidal properties. Chem Biol Interact 291:253263. https://doi.org/10.1016/j.cbi.2018.06.029

Delp J, Gutbier S, Cerff M et al (2018a) Stage-specific metabolic features of differentiating neurons: implications for toxicant sensitivity. Toxicol Appl Pharmacol 354:64-80. https://doi. org/10.1016/j.taap.2017.12.013

Delp J, Gutbier S, Klima S et al (2018b) A high-throughput approach to identify specific neurotoxicants/developmental toxicants in human neuronal cell function assays. ALTEX 4:1. https://doi. org/10.14573/altex.1712182

Desprez B, Dent M, Keller D et al (2018) A strategy for systemic toxicity assessment based on non-animal approaches: the cosmetics Europe long range science strategy programme. Toxicol In Vitro 50:137-146. https://doi.org/10.1016/j.tiv.2018.02.017

Divakaruni AS, Rogers GW, Murphy AN (2014) Measuring mitochondrial function in permeabilized cells using the seahorse XF analyzer or a Clark-type oxygen electrode. Curr Protoc Toxicol 60:25. https://doi.org/10.1002/0471140856.tx2502s60

Dott W, Mistry P, Wright J, Cain K, Herbert KE (2014) Modulation of mitochondrial bioenergetics in a skeletal muscle cell line model of mitochondrial toxicity. Redox Biol 2:224-233. https://doi. org/10.1016/j.redox.2013.12.028 
Dragovic S, Vermeulen NP, Gerets HH et al (2016) Evidence-based selection of training compounds for use in the mechanismbased integrated prediction of drug-induced liver injury in man. Arch Toxicol 90(12):2979-3003. https://doi.org/10.1007/ s00204-016-1845-1

Dreinert A, Wolf A, Mentzel T, Meunier B, Fehr M (2018) The cytochrome bc1 complex inhibitor Ametoctradin has an unusual binding mode. Biochim Biophys Acta 1859(8):567-576. https://doi.org/10.1016/j.bbabio.2018.04.008

Eakins J, Bauch C, Woodhouse $\mathrm{H}$ et al (2016) A combined in vitro approach to improve the prediction of mitochondrial toxicants. Toxicol In Vitro 34:161-170. https://doi.org/10.1016/j. tiv.2016.03.016

Efremova L, Schildknecht S, Adam M et al (2015) Prevention of the degeneration of human dopaminergic neurons in an astrocyte co-culture system allowing endogenous drug metabolism. Br J Pharmacol 172(16):4119-4132. https://doi.org/10.1111/ bph.13193

Forsby A, Bal-Price AK, Camins A et al (2009) Neuronal in vitro models for the estimation of acute systemic toxicity. Toxicol In Vitro 23(8):1564-1569. https://doi.org/10.1016/j.tiv.2009.07.017

FRAC FRAC (2011) FRAC code list: fungicides sorted by mode of action (including FRAC Code numbering)

Frank CL, Brown JP, Wallace K, Mundy WR, Shafer TJ (2017) From the cover: developmental neurotoxicants disrupt activity in cortical networks on microelectrode arrays: results of screening 86 compounds during neural network formation. Toxicol Sci 160(1):121-135. https://doi.org/10.1093/toxsci/kfx169

Furlong IJ, Mediavilla CL, Ascaso R, Rivas AL, Collins MKL (1998) Induction of apoptosis by valinomycin: mitochondrial permeability transition causes intracellular acidification. Cell Death Differ 5:214. https://doi.org/10.1038/sj.cdd.4400335

Gantner F, Leist M, Jilg S, Germann PG, Freudenberg MA, Tiegs G (1995) Tumor necrosis factor-induced hepatic DNA fragmentation as an early marker of $\mathrm{T}$ cell-dependent liver injury in mice. Gastroenterology 109(1):166-176

Gerencser AA, Neilson A, Choi SW et al (2009) Quantitative microplate-based respirometry with correction for oxygen diffusion. Anal Chem 81(16):6868-6878. https://doi.org/10.1021/ac900 $881 z$

Gonzalez PS, O'Prey J, Cardaci S et al (2018) Mannose impairs tumour growth and enhances chemotherapy. Nature 563(7733):719-723. https://doi.org/10.1038/s41586-018-0729-3

Gustafsson H, Runesson J, Lundqvist J, Lindegren H, Axelsson V, Forsby A (2010) Neurofunctional endpoints assessed in human neuroblastoma SH-SY5Y cells for estimation of acute systemic toxicity. Toxicol Appl Pharmacol 245(2):191-202. https://doi. org/10.1016/j.taap.2010.02.018

Gutbier S, May P, Berthelot S et al (2018a) Major changes of cell function and toxicant sensitivity in cultured cells undergoing mild, quasi-natural genetic drift. Arch Toxicol. https://doi.org/10.1007/ s00204-018-2326-5

Gutbier S, Spreng AS, Delp J et al (2018b) Prevention of neuronal apoptosis by astrocytes through thiol-mediated stress response modulation and accelerated recovery from proteotoxic stress. Cell Death Differ 25(12):2101-2117. https://doi.org/10.1038/ s41418-018-0229-x

Harrill JA, Freudenrich TM, Robinette BL, Mundy WR (2011) Comparative sensitivity of human and rat neural cultures to chemicalinduced inhibition of neurite outgrowth. Toxicol Appl Pharmacol 256(3):268-280. https://doi.org/10.1016/j.taap.2011.02.013

Harrill JA, Freudenrich T, Wallace K, Ball K, Shafer TJ, Mundy WR (2018) Testing for developmental neurotoxicity using a battery of in vitro assays for key cellular events in neurodevelopment. Toxicol Appl Pharmacol 354:24-39. https://doi.org/10.1016/j. taap.2018.04.001
He Y, Akumuo RC, Yang Y, Hewett SJ (2017) Mice deficient in L-12/15 lipoxygenase show increased vulnerability to 3-nitropropionic acid neurotoxicity. Neurosci Lett 643:65-69. https:// doi.org/10.1016/j.neulet.2017.02.031

Hendriks HS, Meijer M, Muilwijk M, van den Berg M, Westerink RH (2014) A comparison of the in vitro cyto- and neurotoxicity of brominated and halogen-free flame retardants: prioritization in search for safe(r) alternatives. Arch Toxicol 88(4):857-869. https ://doi.org/10.1007/s00204-013-1187-1

Hoelting L, Klima S, Karreman C et al (2016) Stem cell-derived immature human dorsal root ganglia neurons to identify peripheral neurotoxicants. Stem Cells Transl Med 5(4):476-487. https:// doi.org/10.5966/sctm.2015-0108

Huang Q, Cao H, Zhan L et al (2017) Mitochondrial fission forms a positive feedback loop with cytosolic calcium signaling pathway to promote autophagy in hepatocellular carcinoma cells. Cancer Lett 403:108-118. https://doi.org/10.1016/j.canlet.2017.05.034

Indo HP, Davidson M, Yen H-C et al (2007) Evidence of ROS generation by mitochondria in cells with impaired electron transport chain and mitochondrial DNA damage. Mitochondrion 7(1):106118. https://doi.org/10.1016/j.mito.2006.11.026

Jennings P, Schwarz M, Landesmann B et al (2014) SEURAT-1 liver gold reference compounds: a mechanism-based review. Arch Toxicol 88(12):2099-2133. https://doi.org/10.1007/s0020 4-014-1410-8

Jones W, Bianchi K (2015) Aerobic glycolysis: beyond proliferation. Front Immunol 6:227. https://doi.org/10.3389/fimmu.2015.00227

Kamalian L, Chadwick AE, Bayliss M et al (2015) The utility of HepG2 cells to identify direct mitochondrial dysfunction in the absence of cell death. Toxicol In Vitro 29(4):732-740. https:// doi.org/10.1016/j.tiv.2015.02.011

Kinsner-Ovaskainen A, Prieto P, Stanzel S, Kopp-Schneider A (2013) Selection of test methods to be included in a testing strategy to predict acute oral toxicity: an approach based on statistical analysis of data collected in phase 1 of the ACuteTox project. Toxicol In Vitro 27(4):1377-1394. https://doi.org/10.1016/j. tiv.2012.11.010

Kohonen P, Parkkinen JA, Willighagen EL et al (2017) A transcriptomics data-driven gene space accurately predicts liver cytopathology and drug-induced liver injury. Nat Commun 8:15932. https ://doi.org/10.1038/ncomms 15932

Krug AK, Balmer NV, Matt F, Schonenberger F, Merhof D, Leist M (2013) Evaluation of a human neurite growth assay as specific screen for developmental neurotoxicants. Arch Toxicol 87(12):2215-2231. https://doi.org/10.1007/s00204-013-1072-y

Krug AK, Gutbier S, Zhao L et al (2014) Transcriptional and metabolic adaptation of human neurons to the mitochondrial toxicant MPP(+). Cell Death Dis 5:e1222. https://doi.org/10.1038/cddis .2014 .166

Latta M, Kunstle G, Leist M, Wendel A (2000) Metabolic depletion of ATP by fructose inversely controls CD95- and tumor necrosis factor receptor 1-mediated hepatic apoptosis. J Exp Med 191(11):1975-1985

Leist M, Nicotera P (1998) Calcium and neuronal death. Rev Physiol Biochem Pharmacol 132:79-125

Leist M, Gantner F, Bohlinger I, Tiegs G, Germann PG, Wendel A (1995) Tumor necrosis factor-induced hepatocyte apoptosis precedes liver failure in experimental murine shock models. Am J Pathol 146(5):1220-1234

Leist M, Fava E, Montecucco C, Nicotera P (1997a) Peroxynitrite and nitric oxide donors induce neuronal apoptosis by eliciting autocrine excitotoxicity. Eur J Neurosci 9(7):1488-1498

Leist M, Single B, Castoldi AF, Kuhnle S, Nicotera P (1997b) Intracellular adenosine triphosphate (ATP) concentration: a switch in the decision between apoptosis and necrosis. J Exp Med 185(8):1481-1486 
Leist M, Volbracht C, Kuhnle S, Fava E, Ferrando-May E, Nicotera $P(1997 c)$ Caspase-mediated apoptosis in neuronal excitotoxicity triggered by nitric oxide. Mol Med (Cambridge, Mass) 3(11):750-764

Leist M, Volbracht C, Fava E, Nicotera P (1998) 1-Methyl-4-phenylpyridinium induces autocrine excitotoxicity, protease activation, and neuronal apoptosis. Mol Pharmacol 54(5):789-801

Leist M, Single B, Naumann H et al (1999) Nitric oxide inhibits execution of apoptosis at two distinct ATP-dependent steps upstream and downstream of mitochondrial cytochrome c release. Biochem Biophys Res Commun 258(1):215-221. https ://doi.org/10.1006/bbrc.1999.0491

Levy RJ (2017) Carbon monoxide and anesthesia-induced neurotoxicity. Neurotoxicol Teratol 60:50-58. https://doi.org/10.1016/j. ntt.2016.09.002

Li H, Zhu X-L, Yang W-C, Yang G-F (2014) Comparative kinetics of Qi site inhibitors of cytochrome bc1 complex: picomolar antimycin and micromolar cyazofamid. Chem Biol Drug Des 83(1):71-80. https://doi.org/10.1111/cbdd.12199

Lümmen P (1998) Complex I inhibitors as insecticides and acaricides. Biochim Biophys Acta Bioenerg 1364(2):287-296. https ://doi.org/10.1016/S0005-2728(98)00034-6

Lunt SY, Vander Heiden MG (2011) Aerobic glycolysis: meeting the metabolic requirements of cell proliferation. Annu Rev Cell Dev Biol 27:441-464. https://doi.org/10.1146/annurev-cellb io-092910-154237

Marroquin LD, Hynes J, Dykens JA, Jamieson JD, Will Y (2007) Circumventing the Crabtree effect: replacing media glucose with galactose increases susceptibility of HepG2 cells to mitochondrial toxicants. Toxicol Sci 97(2):539-547. https://doi. org/10.1093/toxsci/kfm052

Martin LA, Kennedy BE, Karten B (2016) Mitochondrial cholesterol: mechanisms of import and effects on mitochondrial function. J Bioenerg Biomembr 48(2):137-151. https://doi. org/10.1007/s10863-014-9592-6

Mitani M, Yamanishi T, Miyazaki Y (1975) Salinomycin: a new monovalent cation ionophore. Biochem Biophys Res Commun 66(4):1231-1236. https://doi.org/10.1016/0006$291 \times(75) 90490-8$

Mitani S, Araki S, Takii Y, Ohshima T, Matsuo N, Miyoshi H (2001) The biochemical mode of action of the novel selective fungicide cyazofamid: specific inhibition of mitochondrial complex III in Pythium spinosum. Pestic Biochem Physiol 71(2):107115. https://doi.org/10.1006/pest.2001.2569

Nadanaciva S, Dykens JA, Bernal A, Capaldi RA, Will Y (2007) Mitochondrial impairment by PPAR agonists and statins identified via immunocaptured OXPHOS complex activities and respiration. Toxicol Appl Pharmacol 223(3):277-287. https:// doi.org/10.1016/j.taap.2007.06.003

Nadanaciva S, Rana P, Beeson GC et al (2012) Assessment of druginduced mitochondrial dysfunction via altered cellular respiration and acidification measured in a 96-well platform. $\mathrm{J}$ Bioenerg Biomembr 44(4):421-437. https://doi.org/10.1007/ s10863-012-9446-Z

Nauen R, Bretschneider T (2002) New modes of action of insecticides. Pestic Outlook 13(6):241-245. https://doi.org/10.1039/ B211171N

Naujokat C, Fuchs D, Opelz G (2010) Salinomycin in cancer: a new mission for an old agent. Mol Med Rep 3(4):555-559. https:// doi.org/10.3892/mmr_00000296

Nicklas WJ, Vyas I, Heikkila RE (1985) Inhibition of NADH-linked oxidation in brain mitochondria by 1-methyl-4-phenyl-pyridine, a metabolite of the neurotoxin, 1-methyl-4-phenyl1,2,5,6-tetrahydropyridine. Life Sci 36(26):2503-2508
Nicotera P, Leist M (1997) Energy supply and the shape of death in neurons and lymphoid cells. Cell Death Differ 4(6):435-442. https://doi.org/10.1038/sj.cdd.4400265

Nicotera P, Leist M, Manzo L (1999) Neuronal cell death: a demise with different shapes. Trends Pharmacol Sci 20(2):46-51

Nordin-Andersson M, Walum E, Kjellstrand P, Forsby A (2003) Acrylamide-induced effects on general and neurospecific cellular functions during exposure and recovery. Cell Biol Toxicol 19(1):43-51

O'Riordan TC, Fitzgerald K, Ponomarev GV et al (2007) Sensing intracellular oxygen using near-infrared phosphorescent probes and live-cell fluorescence imaging. Am J Physiol Regul Integrat Compar Physiol 292(4):R1613-R1620. https://doi. org/10.1152/ajpregu.00707.2006

Pereira CV, Oliveira PJ, Will Y, Nadanaciva S (2012) Mitochondrial bioenergetics and drug-induced toxicity in a panel of mouse embryonic fibroblasts with mitochondrial DNA single nucleotide polymorphisms. Toxicol Appl Pharmacol 264(2):167-181. https://doi.org/10.1016/j.taap.2012.07.030

Pereira SP, Deus CM, Serafim TL, Cunha-Oliveira T, Oliveira PJ (2018) Metabolic and phenotypic characterization of human skin fibroblasts after forcing oxidative capacity. Toxicol Sci 164(1):191-204. https://doi.org/10.1093/toxsci/kfy068

Pessayre D, Fromenty B, Berson A et al (2012) Central role of mitochondria in drug-induced liver injury. Drug Metab Rev 44(1):34-87. https://doi.org/10.3109/03602532.2011.604086

Pietzke M, Zasada C, Mudrich S, Kempa S (2014) Decoding the dynamics of cellular metabolism and the action of 3-bromopyruvate and 2-deoxyglucose using pulsed stable isotope-resolved metabolomics. Cancer Metab 2(9):9. https:// doi.org/10.1186/2049-3002-2-9

Poltl D, Schildknecht S, Karreman C, Leist M (2012) Uncoupling of ATP-depletion and cell death in human dopaminergic neurons. Neurotoxicology 33(4):769-779. https://doi.org/10.1016/j. neuro.2011.12.007

Porporato PE, Payen VL, Baselet B, Sonveaux P (2016) Metabolic changes associated with tumor metastasis, part 2: mitochondria, lipid and amino acid metabolism. Cell Mol Life Sci 73(7):1349-1363. https://doi.org/10.1007/s00018-015-2100-2

Rana P, Aleo MD, Gosink M, Will Y (2018) Evaluation of in vitro mitochondrial toxicity assays and physicochemical properties for prediction of organ toxicity using 228 pharmaceutical drugs. Chem Res Toxicol. https://doi.org/10.1021/acs.chemr estox. $8 \mathrm{~b} 00246$

Reitzer LJ, Wice BM, Kennell D (1979) Evidence that glutamine, not sugar, is the major energy source for cultured HeLa cells. J Biol Chem 254(8):2669-2676

Robinson BH, Petrova-Benedict R, Buncic JR, Wallace DC (1992) Nonviability of cells with oxidative defects in galactose medium: a screening test for affected patient fibroblasts. Biochem Med Metab Biol 48(2):122-126. https://doi. org/10.1016/0885-4505(92)90056-5

Salabei JK, Gibb AA, Hill BG (2014) Comprehensive measurement of respiratory activity in permeabilized cells using extracellular flux analysis. Nat Protoc 9(2):421-438. https://doi. org/10.1038/nprot.2014.018

Schildknecht S, Poltl D, Nagel DM et al (2009) Requirement of a dopaminergic neuronal phenotype for toxicity of low concentrations of 1-methyl-4-phenylpyridinium to human cells. Toxicol Appl Pharmacol 241(1):23-35. https://doi.org/10.1016/j. taap.2009.07.027

Schildknecht S, Karreman C, Poltl D et al (2013) Generation of genetically-modified human differentiated cells for toxicological tests and the study of neurodegenerative diseases. Altex 30(4):427-444. https://doi.org/10.14573/altex.2013.4.427 
Schildknecht S, Di Monte DA, Pape R, Tieu K, Leist M (2017) Tipping points and endogenous determinants of nigrostriatal degeneration by MPTP. Trends Pharmacol Sci 38(6):541-555. https://doi. org/10.1016/j.tips.2017.03.010

Schmidt BZ, Lehmann M, Gutbier S et al (2017) In vitro acute and developmental neurotoxicity screening: an overview of cellular platforms and high-throughput technical possibilities. Arch Toxicol 91(1):1-33. https://doi.org/10.1007/s00204-016-1805-9

Schmuck G, Kahl R (2009) The use of Fluoro-Jade in primary neuronal cell cultures. Arch Toxicol 83(4):397-403. https://doi. org/10.1007/s00204-008-0360-4

Scholz D, Poltl D, Genewsky A et al (2011) Rapid, complete and large-scale generation of post-mitotic neurons from the human LUHMES cell line. J Neurochem 119(5):957-971. https://doi. org/10.1111/j.1471-4159.2011.07255.x

Schultz L, Zurich MG, Culot M et al (2015) Evaluation of drug-induced neurotoxicity based on metabolomics, proteomics and electrical activity measurements in complementary CNS in vitro models. Toxicol In Vitro 30(1 Pt A):138-165. https://doi.org/10.1016/j. tiv.2015.05.016

Secker PF, Beneke S, Schlichenmaier N et al (2018) Canagliflozin mediated dual inhibition of mitochondrial glutamate dehydrogenase and complex I: an off-target adverse effect. Cell Death Dis 9(2):226. https://doi.org/10.1038/s41419-018-0273-y

Senkowski W, Zhang X, Olofsson MH et al (2015) Three-dimensional cell culture-based screening identifies the anthelmintic drug nitazoxanide as a candidate for treatment of colorectal cancer. Mol Cancer Ther 14(6):1504-1516. https://doi.org/10.1158/15357163.Mct-14-0792

Sherer TB, Richardson JR, Testa CM et al (2007) Mechanism of toxicity of pesticides acting at complex I: relevance to environmental etiologies of Parkinson's disease. J Neurochem 100(6):14691479. https://doi.org/10.1111/j.1471-4159.2006.04333.x

Stiegler NV, Krug AK, Matt F, Leist M (2011) Assessment of chemical-induced impairment of human neurite outgrowth by multiparametric live cell imaging in high-density cultures. Toxicol Sci 121(1):73-87. https://doi.org/10.1093/toxsci/kfr034

Swiss R, Niles A, Cali JJ, Nadanaciva S, Will Y (2013) Validation of a HTS-amenable assay to detect drug-induced mitochondrial toxicity in the absence and presence of cell death. Toxicol In Vitro 27(6):1789-1797. https://doi.org/10.1016/j.tiv.2013.05.007

Terrasso AP, Pinto C, Serra M et al (2015) Novel scalable 3D cell based model for in vitro neurotoxicity testing: combining human differentiated neurospheres with gene expression and functional endpoints. J Biotechnol 205:82-92. https://doi.org/10.1016/j. jbiotec.2014.12.011

Terron A, Bal-Price A, Paini A et al (2018) An adverse outcome pathway for parkinsonian motor deficits associated with mitochondrial complex I inhibition. Arch Toxicol 92(1):41-82. https://doi. org/10.1007/s00204-017-2133-4

Tilmant K, Gerets H, De Ron P, Hanon E, Bento-Pereira C, Atienzar FA (2018) In vitro screening of cell bioenergetics to assess mitochondrial dysfunction in drug development. Toxicol In Vitro 52:374-383. https://doi.org/10.1016/j.tiv.2018.07.012

Tirmenstein MA, Hu CX, Gales TL et al (2002) Effects of troglitazone on HepG2 viability and mitochondrial function. Toxicol Sci 69(1):131-138

Tong ZB, Hogberg H, Kuo D et al (2017) Characterization of three human cell line models for high-throughput neuronal cytotoxicity screening. J Appl Toxicol 37(2):167-180. https://doi. org/10.1002/jat.3334
Tong ZB, Huang R, Wang Y et al (2018) The toxmatrix: chemogenomic profiling identifies interactions that reveal mechanisms of toxicity. Chem Res Toxicol 31(2):127-136. https://doi. org/10.1021/acs.chemrestox.7b00290

van Thriel C, Levin E, Lein P, Costa LG, Westerink RH (2017) Neural mechanisms of functional impairment across the lifespan: the 15th biennial meeting of the international neurotoxicology association and 39th annual meeting of the neurobehavioral teratology society. Neurotoxicology 59:131-132. https://doi. org/10.1016/j.neuro.2017.03.003

Volbracht C, Leist M, Nicotera P (1999) ATP controls neuronal apoptosis triggered by microtubule breakdown or potassium deprivation. Mol Med (Cambridge, Mass) 5(7):477-489

Wajner M, Amaral AU (2015) Mitochondrial dysfunction in fatty acid oxidation disorders: insights from human and animal studies. Biosci Rep 36(1):e00281. https://doi.org/10.1042/bsr20150240

Westwood FR, Bigley A, Randall K, Marsden AM, Scott RC (2005) Statin-induced muscle necrosis in the rat: distribution, development, and fibre selectivity. Toxicol Pathol 33(2):246-257. https ://doi.org/10.1080/01926230590908213

Will Y, Dykens J (2014) Mitochondrial toxicity assessment in industry - a decade of technology development and insight. Expert Opin Drug Metab Toxicol 10(8):1061-1067. https://doi. org/10.1517/17425255.2014.939628

Wilson MS, Graham JR, Ball AJ (2014) Multiparametric high content analysis for assessment of neurotoxicity in differentiated neuronal cell lines and human embryonic stem cell-derived neurons. Neurotoxicology 42:33-48. https://doi.org/10.1016/j.neuro 2014.03.013

Witt B, Meyer S, Ebert F, Francesconi KA, Schwerdtle T (2017) Toxicity of two classes of arsenolipids and their water-soluble metabolites in human differentiated neurons. Arch Toxicol 91(9):31213134. https://doi.org/10.1007/s00204-017-1933-x

Wolters JEJ, van Breda SGJ, Grossmann J, Fortes C, Caiment F, Kleinjans JCS (2018) Integrated 'omics analysis reveals new druginduced mitochondrial perturbations in human hepatocytes. Toxicol Lett 289:1-13. https://doi.org/10.1016/j.toxlet.2018.02.026

Xia M, Huang R, Shi Q et al (2018) Comprehensive analyses and prioritization of Tox $2110 \mathrm{~K}$ chemicals affecting mitochondrial function by in-depth mechanistic studies. Environ Health Perspect 126(7):077010. https://doi.org/10.1289/ehp2589

Yu LP, Xiang S, Lasso G, Gil D, Valle M, Tong L (2009) A symmetrical tetramer for $S$. aureus pyruvate carboxylase in complex with coenzyme A. Structure (London, England : 1993) 17(6):823832. https://doi.org/10.1016/j.str.2009.04.008

Zhang Y, Avalos JL (2017) Traditional and novel tools to probe the mitochondrial metabolism in health and disease. Wiley Interdiscip Rev Syst Biol Med 9:2. https://doi.org/10.1002/wsbm.1373

Zhang CQ, Liu YH, Ma XY, Feng Z, Ma ZH (2009) Characterization of sensitivity of Rhizoctonia solani, causing rice sheath blight, to mepronil and boscalid. Crop Protection 28(5):381-386. https ://doi.org/10.1016/j.cropro.2008.12.004

Zimmer B, Schildknecht S, Kuegler PB, Tanavde V, Kadereit S, Leist M (2011) Sensitivity of dopaminergic neuron differentiation from stem cells to chronic low-dose methylmercury exposure. Toxicol Sci 121(2):357-367. https://doi.org/10.1093/toxsci/kfr054

Publisher's Note Springer Nature remains neutral with regard to jurisdictional claims in published maps and institutional affiliations. 


\section{Affiliations}

Johannes Delp ${ }^{1,2}\left(\right.$ Melina Funke $^{1} \cdot$ Franziska Rudolf $^{1} \cdot$ Andrea Cediel $^{3} \cdot$ Susanne Hougaard Bennekou ${ }^{4}$. Wanda van der Stel ${ }^{5} \cdot$ Giada Carta $^{6} \cdot$ Paul Jennings $^{6} \cdot$ Cosimo Toma $^{7} \cdot$ Iain Gardner $^{8} \cdot$ Bob van de Water $^{5}$. Anna Forsby ${ }^{3,9} \cdot$ Marcel Leist $^{1}$

1 Chair for In Vitro Toxicology and Biomedicine, Department of Inaugurated by the Doerenkamp-Zbinden Foundation, University of Konstanz, Universitaetsstr. 10, 78457 Constance, Germany

2 Cooperative Doctorate College InViTe, University of Konstanz, Constance, Germany

3 Swetox Unit for Toxicological Sciences, Karolinska Institutet, Stockholm, Sweden

4 National Food Institute, Technical University of Denmark (DTU), Lyngby, Denmark

5 Division of Drug Discovery and Safety, Leiden Academic Centre for Drug Research, Leiden University, Einsteinweg 55, 2333 CC Leiden, The Netherlands
6 Division of Molecular and Computational Toxicology, Amsterdam Institute for Molecules, Medicines and Systems, Vrije Universiteit Amsterdam, Amsterdam, The Netherlands

7 Laboratory of Environmental Chemistry and Toxicology, Department of Environmental Health Sciences, Istituto di Ricerche Farmacologiche Mario Negri IRCCS, Via la Masa 19, 20156 Milan, Italy

8 Certara UK Limited, Sheffield, UK

9 Department of Biochemistry and Biophysics, Stockholm University, Stockholm, Sweden 